\title{
Springback of Friction Stir Welded Sheets Made of Aluminium Grades during V-Bending: An Experimental Study
}

\author{
B. Durga Rao and R. Ganesh Narayanan \\ Department of Mechanical Engineering, IIT Guwahati, Guwahati, Assam 781039, India \\ Correspondence should be addressed to R. Ganesh Narayanan; ganu@iitg.ernet.in
}

Received 12 November 2013; Accepted 13 February 2014; Published 18 March 2014

Academic Editors: A. Combescure, X. Yang, and G. Zhao

Copyright ( 2014 B. Durga Rao and R. Ganesh Narayanan. This is an open access article distributed under the Creative Commons Attribution License, which permits unrestricted use, distribution, and reproduction in any medium, provided the original work is properly cited.

\begin{abstract}
The main aim of the present work is to study the effect of shoulder diameter, rotational speed, and welding speed on the springback performance of friction stir welded sheets. The friction stir welded sheets are made by welding 6061T6 to 5052H32, and 6061T6 to 6061T6. The springback has been evaluated after V-bending of welded sheets, involving pure bending. The relation between springback and weld zone properties like yield strength, Young's modulus, yield strength to Young's modulus ratio, and strain hardening exponent is identified. It is found that, with increase in shoulder diameter, rotational speed, and welding speed, the springback of friction stir welded sheets has reduced, and is independent of the material combinations. The relation between springback and weld properties change coincides with existing knowledge about springback. The friction stir welded sheets show better springback performance as compared to $6061 \mathrm{~T} 6$ base material, but inferior to $5052 \mathrm{H} 32$ base material. By reducing the punch nose radius, the springback of friction stir welded sheets can be minimized. It is also concluded that, by proper tailoring of $\mathrm{Al}$ grades, and by alteration of weld zone properties through friction stir welding, the springback of friction stir welded sheets can be reduced considerably.
\end{abstract}

\section{Introduction}

Friction stir welding (FSW) is a solid state welding process, in which a nonconsumable rotating tool with a pin at its end is plunged into the adjoining sheets or plates and is traversed along the contact edge resulting in joining of sheets. The tool generates heat as it contacts the sheets and it helps in material plastic deformation, ensuring joint formation. The heat is generated by friction between the tool and the sheets and plastic deformation of sheets [1]. Depending on the rotation speed and welding speed, the material moves from front side of the pin to its back. There are many advantages of FSW including energy savings, exclusion of consumables and shielding gases, good dimensional stability, low distortion of work sheet, enhanced metallurgical properties in the weld region, fine microstructure, possibility of welding dissimilar materials, and reduced usage of fasteners for joining multiple parts. Because of the environmental friendliness and energy efficiency, it is considered as "green technology."
Tailor Welded Blanks (TWB) consist of sheets of similar or dissimilar thicknesses, quality, coatings, and so forth, welded in a single plane before forming. In the automotive sector, the applications of TWB include hoods, deck lids, floor and door inner panels, and side frame rails. FSW is one of the welding processes used to fabricate tailor welded sheets, made of aluminium alloys. There are attempts to join steel grades through FSW process.

The dimensional accuracy of formed sheet parts is critical to ensure the quality during their industrial usage. Any small change in dimensions will not allow the parts to have compatibility with their mating parts, and compensation for that is reasonably complex. Springback of sheets is one such phenomenon that deteriorates the quality of sheet products through dimensional change. This is caused mainly by the release of internal elastic stresses from the sheet, when it is unloaded. Overbending, bottoming, and stretch bending are common methods of controlling springback [2]. There are other methods like heat treating the materials, change 
in working temperature of material and tools, appropriate tool design, tool geometry design which are also used for springback control of sheets. Moon et al. [3] demonstrated that the hot die and cold punch combination can reduce the springback of $\mathrm{Al} 1050$ sheet up to $20 \%$ when compared to conventional bending done at room temperature. The ram speed was also shown to have significant effect on controlling springback. The multidirectional springback occurring in industrial sheet parts was simulated through an elliptical punch-die set up [4]. There was primary springback in the longitudinal direction and secondary springback in the transverse direction of the strip along the side wall. The numerical simulations were conducted for strip drawing (using explicit time integration scheme) and springback after drawing (using implicit time integration scheme). The comparison between experimental and simulations results are matching well [4]. Garcia-Romeu et al. [5] have shown through experiments that sheet materials, their thicknesses, and die widths affect the springback behaviour in a compounding fashion. It has been concluded by them that though small radius is preferred for springback, and large radius dies are preferred in consideration of mechanical properties of bent part. Hence one should optimize various factors governing the springback of sheets. The unconstrained springback of Al-Mg-Si sheets is analyzed by de Sousa et al. [6], by taking into account that the sheets are prestrained before the actual deformation and later subjected to different sitting times at normal temperatures. The effective stress distribution from numerical simulations shows that extensive amount of stress is relaxed when the punch is totally released. It is also observed through experiments and simulations that the springback angle decreases as the sitting time increases.

The experimental study of the split-ring test on AA5754$\mathrm{O}$ aluminium alloy for several temperatures in the range 25$200^{\circ} \mathrm{C}$ was demonstrated [7]. The results from their study show that the effect of temperature decreases the stress gradient in the cup wall, because of which the springback opening of the ring decreases. A study of time-dependent springback on Al alloys like 2008-T4, 5182-O, 6022-T4, and 6111-T4 after draw-bend tests was performed [8]. The springback angle measurements were taken for 15 months and compared for analyses. Generally the springback is proportional to log (time) up to few months, after which no effect was observed. Two important mechanisms, namely, creep driven by residual stress and anelasticity are proposed to be responsible for time-dependent springback. But finally after careful experimentation and simulations, it was concluded that anelasticity is unlikely to play large role in long term time-dependent springback, but it can contribute to short-term response. Though in this work, the authors reported that time-dependent springback is absent in forming steels, the work done by Lim et al. [9] showed that Advanced High Strength Steels (AHSS) like dual phase (DP) steel, transformation induced plasticity (TRIP) steel, and conventional steels also show time-dependent springback. Even in AHSS, creep driven by residual stress is responsible for time-dependent springback, rather than anelasticity. The springback found in AHSS is approximately $1 / 3 \mathrm{rd}$ of that for aluminum alloys mentioned in Wang et al.s [8] work.
The study of Wang et al. and Lim et al. revealed that the time at which springback is measured also influences the final accuracy of controlling and compensating strategies for springback.

The springback free phenomenon during warm forming of precipitation-hardened high-strength steel above $750 \mathrm{~K}$ was analysed by Yanagimoto and Oyamada [10]. The significant decrease of springback at $773 \mathrm{~K}$ for the material is caused by the increase of high-temperature creep strain just after loading process, resulting in springback reduction. It is also confirmed by them that the change in flow stress and Young's modulus at elevated temperatures plays an insignificant role in springback reduction. The study of Wang et al. [11] reveals that the springback of AZ31B Mg alloy decreased with increase of forming temperature and decrease of punch radii during V-bending. There is some shift of neutral layer towards tensile zone. The shift of neutral layer is because of asymmetry of deformation from tensile-outer layer, dominated by slip, to compression-inner layer, dominated by twinning. Yu's analyses showed that the elastic modulus decreased with increase in plastic strain of TRIP steel [12]. The decrease is nearly $18 \%$ after a plastic strain of 0.26 . Springback simulation of U-channel part has been conducted with constant and varied elastic modulus, and it is found that springback angles for varied elastic modulus case are closer to the experimental result, which indicates that the inelastic recovery should be considered in order to obtain an accurate springback evaluation.

In the case of Friction Stir (FS) welded sheets, the selection of welding and tool parameters decides the overall forming performance as the weld region will have different mechanical properties and microstructures compared to that of base materials. Park et al. [13] have shown through unconstrained bending tests that, with increase in friction stir probe diameter from $5 \mathrm{~mm}$ to $10 \mathrm{~mm}$, the springback of friction stir (FS) welded made of 5052-H32 sheet of $1.5 \mathrm{~mm}$ thickness has reduced by about $3-5^{\circ}$, in the case of longitudinal weld. Similarly about $4^{\circ}$ decrease in springback was found in transverse weld FSW sheet, with respect to base material. The experimental analysis and finite element prediction (using combined isotropic-kinematic hardening law based on the modified Chaboche model and Yld2000-2d yield function) of springback of FS welded sheets made of three Al alloys and DP steel showed that the material property dependence of springback is prominent for unconstrained cylindrical bending test than the $2 \mathrm{D}$ draw bending test [14]. In those FS welded sheets with transverse weld and softer weld (relative to base metals), the bending was localized, as compared to those having equally hard weld zones. The springback tests like the unconstrained cylindrical bending, 2D draw bending, and draw-bend tests were simulated, and the predictions agree reasonably well with experimental results. Park et al. [15] have again showed that the weld zone ductility has improved with reduction in strength compared to AA5052-H32 base material. The friction processed sheet showed slightly better springback performance as that of base material. Miles et al. [16] work also highlights the importance of FS process in increasing the bending limit of FS welded plates made of 6061-T6 and 7075-T7451. Though the failure models used 
TABLE 1: Tensile properties of AA $6061 \mathrm{~T} 6$.

\begin{tabular}{|c|c|c|c|c|c|c|c|}
\hline Rolling direction & $\sigma_{\mathrm{ys}}(\mathrm{MPa})$ & UTS (MPa) & $\varepsilon_{u}(\%)$ & $\varepsilon_{t}(\%)$ & $n$ & $K(\mathrm{MPa})$ & $R$ \\
\hline $0^{0}$ & $269 \pm 8$ & $312 \pm 11$ & $10.5 \pm 1$ & $12.6 \pm 2$ & 0.08 & $379 \pm 21$ & 0.81 \\
\hline $15^{0}$ & $266 \pm 9$ & $310 \pm 10$ & $9.7 \pm 2$ & $12.6 \pm 1$ & 0.07 & $373 \pm 23$ & 0.75 \\
\hline $30^{\circ}$ & $260 \pm 5$ & $308 \pm 9$ & $10.9 \pm 2$ & $12.6 \pm 2$ & 0.07 & $375 \pm 26$ & 0.8 \\
\hline $45^{0}$ & $259 \pm 11$ & $308 \pm 8$ & $11.7 \pm 1$ & $13.3 \pm 1$ & 0.08 & $378 \pm 21$ & 0.9 \\
\hline $60^{\circ}$ & $273 \pm 7$ & $318 \pm 7$ & $11.2 \pm 2$ & $13.3 \pm 1$ & 0.07 & $387 \pm 18$ & 0.84 \\
\hline $75^{0}$ & $263 \pm 6$ & $311 \pm 8$ & $11.9 \pm 1$ & $13.0 \pm 1$ & 0.08 & $379 \pm 19$ & 0.84 \\
\hline $90^{\circ}$ & $262 \pm 4$ & $309 \pm 8$ & $9.6 \pm 2$ & $11.7 \pm 1$ & 0.08 & $381 \pm 15$ & 0.71 \\
\hline
\end{tabular}

during finite element analysis predicted the necking limits with extreme accuracy in the case of unprocessed $6061 \mathrm{Al}$ plate, their prediction for FS processed plate was moderately accurate. The model accuracy has improved once the gradient of mechanical properties in through thickness direction was captured properly by the stress-strain behaviour. Recently Ramulu et al. [17] studied about the effect of the welding speed and tool rotation speed on the forming limit of FS welded sheets made of AA6061-T6 with thickness of $2.1 \mathrm{~mm}$. With weld oriented along major straining direction in limit dome height test, the results showed that the formability has improved by decreasing welding speed and increasing tool rotation speed. Moreover, the forming limits of FSW sheets are better than the unwelded sheets.

There are a few computer aided engineering based springback compensation methods like " $\mathrm{K}$ \& B" method [18] and "displacement adjustment (DA)" method [19] that can be used to automatically compensate for dimensional changes. In DA method, the surface nodes defining the die surface are moved in the direction opposed to the springback error, while K \& B depends on force equilibrium approach. Both the methods are compared, and it was found that DA converges rapidly and does not rely on part symmetry, while $\mathrm{K} \& \mathrm{~B}$ converges slowly and inaccurate results are found in nonsymmetric parts [19]. These methods combined with accurate time-dependent evaluation of springback of sheets, and optimization of FS welding conditions (like shoulder diameter, rotational speed, welding speed, plunge depth, etc.) in the case of FS welded sheets would provide a valid and efficient ways of predicting and compensating springback.

The welding conditions during FSW will certainly affect the springback of welded sheets like any other forming behaviour including forming limit strain, thickness distribution, weld zone mechanical properties, and so forth. The modified weld zone properties are in turn related to final overall FS welded sheet formability including springback. The main aim of the present work is to (i) study the effect of shoulder diameter, welding speed, and rotational speed on the springback of FS welded sheets made of dissimilar (6061T6-5052H32) and similar (6061T6-6061T6) Al alloys of $2.1 \mathrm{~mm}$ thickness and (ii) relate the dimension change to alteration of yield strength, strain hardening exponent, and Young's modulus of weld zone at different FS welding conditions. The effect of punch nose radius on springback of welded sheets is also briefly presented. A V-bending setup, consisting die and punch, has been fabricated to deform the sheet involving pure bending and to evaluate springback.

\section{Materials and Methods}

2.1. Mechanical Properties of Base Materials. AA6061T6 and AA5052H32 aluminium sheets of $2.1 \mathrm{~mm}$ thickness are used as base materials for the present work. The mechanical and forming properties of the base material were obtained from standard tensile tests by following ASTM E646-98 standards. The tensile properties were evaluated at seven different rolling directions, namely, $0^{\circ}, 15^{\circ}, 30^{\circ}, 45^{\circ}, 60^{\circ}, 75^{\circ}$, and $90^{\circ}$. The samples required for tensile testing were made using $\mathrm{CO}_{2}$ laser cutting machine. All the samples were tested in an Instron 8801 machine ( $100 \mathrm{kN}$ capacity) at room temperature with a constant cross-head speed of $1 \mathrm{~mm} / \mathrm{min}$. Three samples were tested in each direction to check the repeatability. The load-extension data from the machine was converted into engineering stress-strain behaviour and the mechanical properties such as yield strength, ultimate tensile strength, uniform elongation, and total elongation were evaluated. The engineering stress-strain behaviour was converted into true stress-strain behaviour to evaluate the strain-hardening exponent $(n)$ and strength coefficient $(K)$ by following a power law equation. The plastic strain ratios $(R)$ were also evaluated at seven different rolling directions by following ASTM E517 standard. In this case, rectangular strips were cut along different directions with respect to rolling direction and deformed till $12 \%$ strain. The longitudinal, transverse, and thickness strains were evaluated to find the plastic strain ratios in seven rolling directions. Three trials were conducted in each rolling direction to check the repeatability. The properties thus evaluated are listed in Tables 1 and 2 for AA6061T6 and AA5052H32, respectively.

\subsection{Friction Stir Welding Experiments}

2.2.1. Dissimilar Grade Combination (6061T6-5052H32). The welding trials were conducted on a machine designed and developed by the Indian Institute of Science, Bangalore, India, and ETA Technologies, Bangalore, India. The machine has exclusive capability in which the plunge depth, rotational speed, or weld speed could be varied within a test. The initial FSW trials were performed within selected range of welding parameters like $600-1500 \mathrm{rpm}$ for rotational speed, 


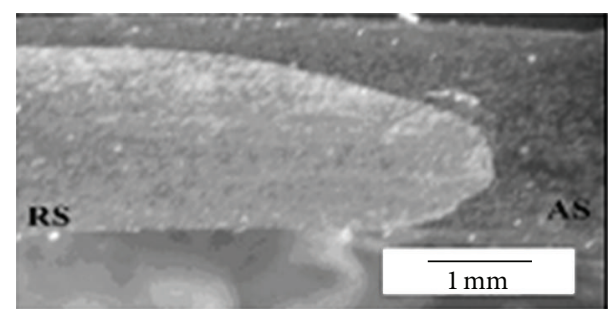

(A)

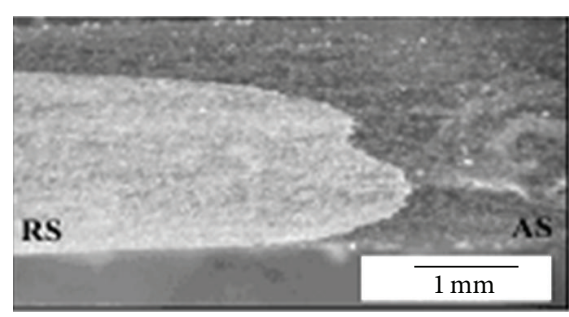

(B)

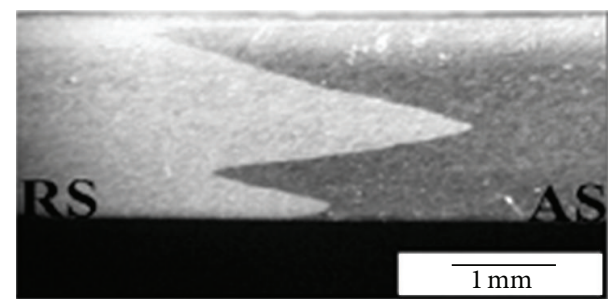

(C)

(a)

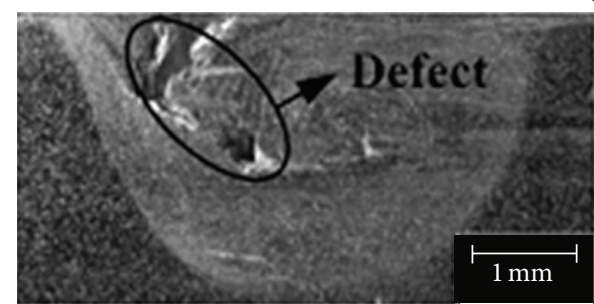

(A)

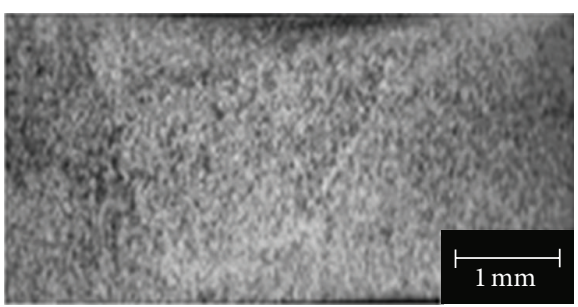

(B)

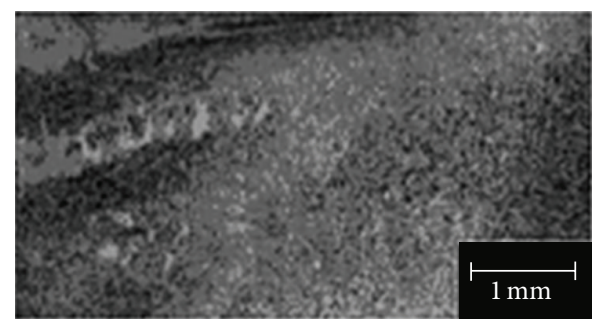

(C)

(b)

FIgURE 1: (a) Macrostructures of weld at different welding conditions for 6061T6-5052H32 sheet combination (dissimilar Al grades): (A) rotational speed: $1500 \mathrm{rpm}$; plunge depth $=1.95 \mathrm{~mm}$; shoulder diameter $=16 \mathrm{~mm}$; welding speed $=80 \mathrm{~mm} / \mathrm{min}$; (B) rotational speed: $1500 \mathrm{rpm}$; plunge depth $=1.95 \mathrm{~mm}$; shoulder diameter $=16 \mathrm{~mm}$; welding speed $=130 \mathrm{~mm} / \mathrm{min} ;(\mathrm{C})$ rotational speed: $1500 \mathrm{rpm}$; plunge depth $=1.95 \mathrm{~mm}$; shoulder diameter $=12 \mathrm{~mm}$; welding speed $=80 \mathrm{~mm} / \mathrm{min}$; RS: $5052 \mathrm{H} 32$, AS: 6061T6. (b) Macrostructures of weld at different welding conditions for 6061T6-6061T6 sheet combination (similar Al grades): (A) rotational speed: $1100 \mathrm{rpm}$; welding speed: $90 \mathrm{~mm} / \mathrm{min}$; shoulder diameter: $18 \mathrm{~mm}$; plunge depth $=1.8 \mathrm{~mm}$ (defective case); (B) rotational speed: $1300 \mathrm{rpm}$; welding speed: $90 \mathrm{~mm} / \mathrm{min}$; shoulder diameter: $12 \mathrm{~mm}$; plunge depth: $1.9 \mathrm{~mm}$; (C) rotational speed: $1350 \mathrm{rpm}$; plunge depth: $1.9 \mathrm{~mm}$; shoulder diameter: $18 \mathrm{~mm}$; welding speed = $120 \mathrm{~mm} / \mathrm{min}$ [17].

60-150 $\mathrm{mm} / \mathrm{min}$ for welding speed, $1.65-1.95 \mathrm{~mm}$ for plunge depth, and 12-18 $\mathrm{mm}$ for shoulder diameter. The above said range was decided based on the previous work done by Kumar et al. [20]. In their work, the range fixed was slightly larger, and at higher levels of rotational speed, say 1800$2000 \mathrm{rpm}$, external flash of about 6-7 mm height was formed. The flash formation was reduced by choosing the lower rotational speed range, $600-1500 \mathrm{rpm}$, in the present work. During these welding trials, one welding parameter, like welding speed is varied continuously between two extreme levels to complete a single weld. Similarly other welding parameters are varied in a single welding trial. This has reduced the number of welding trials and sheet materials drastically by about $65 \%$. Since in Kumar et al's work [20] the optimized welding conditions range was achieved after careful examination of "internal defects," the range followed in the present also yielded internal defect free joints. AA6061T6 was placed on the advancing side (AS) and AA5052H32 on the retreating side (RS) of the weld during welding trials to fabricate FS welded sheets made of dissimilar grades. Figure 1(a) shows the macrostructures of friction stir weld region at chosen welding conditions for dissimilar $\mathrm{Al}$ 
TABLE 2: Tensile properties of AA 5052H32.

\begin{tabular}{|c|c|c|c|c|c|c|c|}
\hline Rolling direction & $\sigma_{\mathrm{ys}}(\mathrm{MPa})$ & UTS (MPa) & $\varepsilon_{u}(\%)$ & $\varepsilon_{t}(\%)$ & $n$ & $K(\mathrm{MPa})$ & $R$ \\
\hline $0^{0}$ & $170 \pm 8$ & $228 \pm 7$ & $11.2 \pm 1$ & $13.4 \pm 2$ & 0.14 & $335 \pm 20$ & 0.92 \\
\hline $15^{0}$ & $166 \pm 9$ & $224 \pm 7$ & $10.2 \pm 1$ & $13.0 \pm 2$ & 0.14 & $330 \pm 22$ & 0.94 \\
\hline $30^{\circ}$ & $163 \pm 7$ & $220 \pm 9$ & $11.9 \pm 2$ & $13.4 \pm 1$ & 0.14 & $321 \pm 26$ & 0.85 \\
\hline $45^{0}$ & $168 \pm 10$ & $225 \pm 8$ & $10.8 \pm 2$ & $13.4 \pm 1$ & 0.14 & $318 \pm 16$ & 0.93 \\
\hline $60^{\circ}$ & $157 \pm 6$ & $218 \pm 8$ & $11.6 \pm 1$ & $13.3 \pm 2$ & 0.15 & $325 \pm 21$ & 0.71 \\
\hline $75^{0}$ & $165 \pm 5$ & $221 \pm 10$ & $11.2 \pm 2$ & $13.7 \pm 2$ & 0.15 & $321 \pm 19$ & 0.72 \\
\hline $90^{\circ}$ & $165 \pm 8$ & $222 \pm 5$ & $9.9 \pm 2$ & $12.6 \pm 1$ & 0.15 & $326 \pm 21$ & 0.85 \\
\hline
\end{tabular}

$\sigma_{\mathrm{ys}}$ : yield strength; UTS: ultimate tensile strength; $\varepsilon_{u}$ : uniform elongation; $\varepsilon_{t}$ : total elongation (at $50 \mathrm{~mm}$ gauge length); $K$ : strength coefficient; $n$ : strain hardening exponent; $R$ : plastic strain ratio.

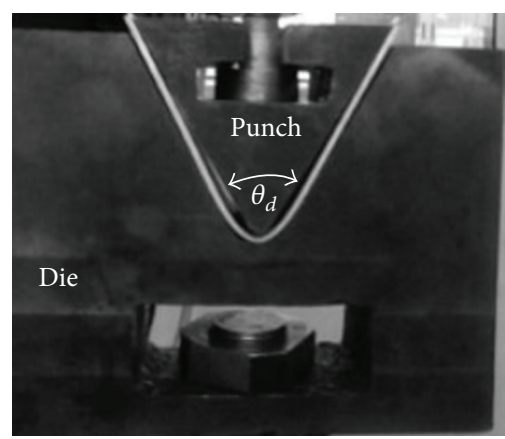

(a)

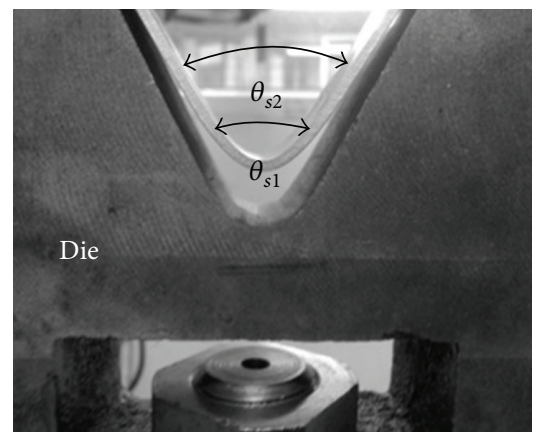

(b)

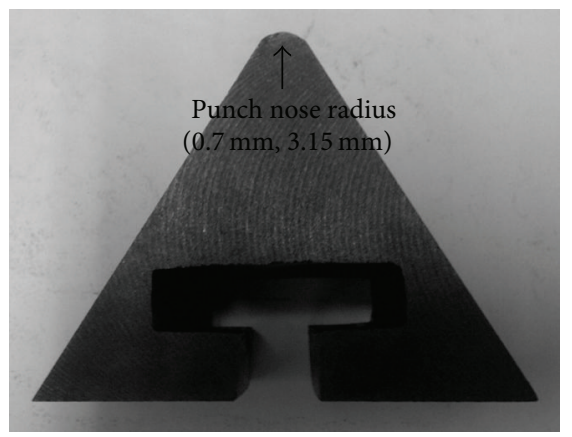

(c)

FIGURE 2: V-bending setup during testing of sheet samples: (a) fully bent sample; (b) sample after retracting punch (removal of load); (c) fabricated punch. Reference die angle: $\theta_{d}$; springback angle near die radius: $\theta_{s 1}$; springback angle far from die radius: $\theta_{s 2}$.

alloy case without defects. Since the welding parameters are varied continuously in a single weld, by knowing the linear variation of one particular parameter, the welding conditions at any length of the weld can be evaluated. This method is followed to check the presence of internal defects in the weld zone. The final optimized welding parameters are fixed at three levels: $12 \mathrm{~mm}, 16 \mathrm{~mm}$, and $18 \mathrm{~mm}$ for shoulder diameter; $600 \mathrm{rpm}, 700 \mathrm{rpm}$, and $800 \mathrm{rpm}$ for rotational speed; and $80 \mathrm{~mm} / \mathrm{min}, 100 \mathrm{~mm} / \mathrm{min}$, and $120 \mathrm{~mm} / \mathrm{min}$ for welding speed. A pin length of $1.7 \mathrm{~mm}$ for each tool was used. The plunge depth and tool tilt angle were kept at a constant value of $1.88 \mathrm{~mm}$ and $2.5^{\circ}$ during welding.

2.2.2. Similar Grade Combination (6061T6-6061T6). A similar methodology was followed during friction stir welding of 6061T6-6061T6 sheets to fabricate FS welded sheets made of similar Al grades. In this case, 6061T6 sheets were placed on retreating and advancing sides of the weld. Initially the welding parameters range was fixed, and macrostructures were evaluated at different lengths of the weld to check the presence of internal weld defects. For initial trials, the welds were produced at tool rotation speeds of $800-$ $1600 \mathrm{rpm}$, at welding speed of $50-130 \mathrm{~mm} / \mathrm{min}$, plunge depth of $1.5-2 \mathrm{~mm}$, and shoulder diameters $12 \mathrm{~mm}, 15 \mathrm{~mm}$, and $18 \mathrm{~mm}$. Depending on the absence of weld defects, the final optimized welding conditions were achieved at two levels as: $12 \mathrm{~mm}, 18 \mathrm{~mm}$ for shoulder diameter; $1300 \mathrm{rpm}, 1400 \mathrm{rpm}$ for rotational speed; $90 \mathrm{~mm} / \mathrm{min}, 100 \mathrm{~mm} / \mathrm{min}$ for welding speed. Though plunge depth is optimized as $1.85 \mathrm{~mm}$ and
$1.9 \mathrm{~mm}$, the effect is not studied on springback in the present work. Figure 1(b) shows some of the macrostructures of weld for similar Al alloys (6061T6-6061T6) combination, with and without defects. A tool tilt angle of $2.5^{\circ}$ was kept constant throughout the process. The pin in the tool was of frustum shape with base diameter $6 \mathrm{~mm}$, top diameter $4 \mathrm{~mm}$, and length $1.7 \mathrm{~mm}$.

2.3. Springback Experiments and Evaluation. All the springback experiments, which are pure bending operations, were conducted in a V-bending setup fabricated through casting and machining. The setup and fixtures were fabricated such that it can be clamped properly in the Instron dynamic testing machine. The punch and die angles were fixed as $60^{\circ}$ from the available literature. Later when they were fabricated, a single die with channel for $\mathrm{V}$-bending with an inclusive angle of $59.2^{\circ}$, radius of curvature of $9.27 \mathrm{~mm}$ at the bend, channel height of $65 \mathrm{~mm}$, and channel width of $90 \mathrm{~mm}$ at the surface was obtained. The angle of $59.2^{\circ}$ was used as reference in the present work. Two different punches were fabricated with different nose radius like $0.7 \mathrm{~mm}$, and $3.15 \mathrm{~mm}$ (Figure 2). For the dissimilar material combination, a punch nose radius of $3.15 \mathrm{~mm}$ was used, while both the punches were used for similar material combination, so that punch nose radius effect can also be studied.

The sheet of size $50 \mathrm{~mm} \times 170 \mathrm{~mm}$ (both unwelded and welded) was placed on the die flat surface. The punch was made to move downwards till it touches the sheet surface. 

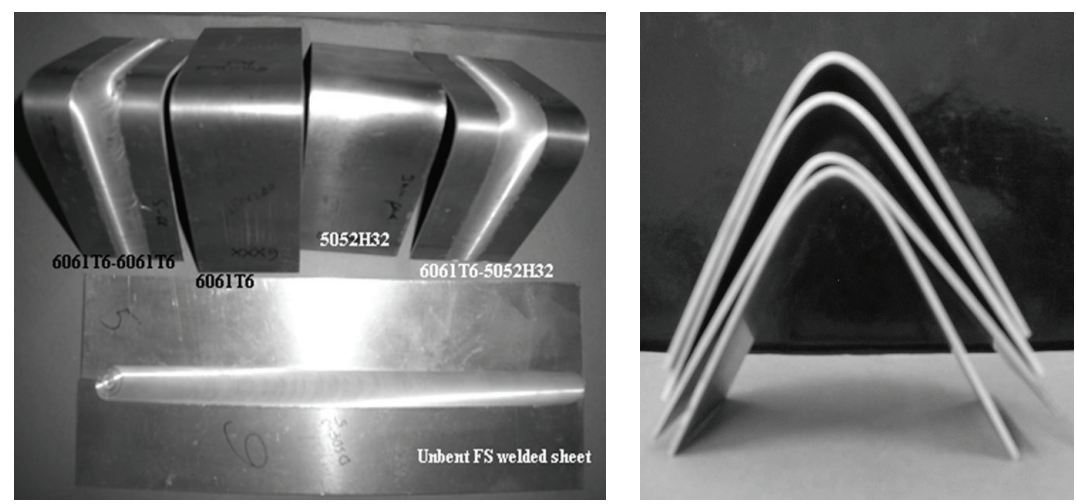

FIGURE 3: Undeformed FS welded sheet and deformed sheets after springback.

After this stage, the punch was moved at the constant crosshead speed of $2 \mathrm{~mm} / \mathrm{min}$ such that it bends the sheet plastically till it takes the contour of the die channel (Figure 2(a)). After this, the punch was immediately retracted, which is equivalent to removal of load after plastic deformation, making the sheet to recover its shape partially (Figure 2(b)). The die angle $\left(\theta_{d}\right)$ was taken as the reference, and the partial shape change in the sheet is quantified with the new angles, $\theta_{s 1}, \theta_{s 2}$, measured called as "springback" angles, in the present work (Figures 2(a) and 2(b)). The springback is considered to be large if the new angle deviates more from the reference die angle. The springback angles were measured at three locations of the bent samples, one very near to the radius of curvature, and the other two far from radius of curvature, say about $40 \mathrm{~mm}$ from near to radius measurement. Two trials were performed in each FSW condition to check the repeatability of the results. The angle near radius $\left(\theta_{s 1}\right)$ was averaged from two angle data from two trials, and the angle far from radius $\left(\theta_{s 2}\right)$ was averaged from four angle data from two trials. These two springback angles are reasonably different in almost all the experiments and hence quantified separately.

Once the V-bending test was completed, the springback angles were measured using profile projector within 24 hours, as it was shown elsewhere $[8,9]$ that Al alloys and AHSS sheet materials show time dependent springback for few months and for few weeks, respectively, because of creep driven by residual stress, and anelasticity. So the springback angles measured in the present work are at common time interval after the test completion. In the case of welded sheets, the weld was oriented along the length dimension of the sample, and they were bent such that the punch touches the bottom surface of the weld. Some of the bent samples after springback are shown in Figure 3.

\section{Results and Discussion}

3.1. Microstructures of Welded Joints. The microstructures of joints made during friction stir welding of $5052 \mathrm{H} 32$ $6061 T 6$ grades (dissimilar materials) for two different welding conditions are shown in Figures 4(a)-4(d). The standard metallographic procedure of mounting the sample showing the surface along the thickness, polishing the samples with different grades of abrasive sheets, and with diamond paste was followed to obtain a scratch free surface. Then etching was done using Keller's reagent $\left(2.5 \mathrm{~mL} \mathrm{HNO}_{3}+1.5 \mathrm{~mL} \mathrm{HCl}\right.$ $\left.+1 \mathrm{~mL} \mathrm{HF}+95 \mathrm{~mL} \mathrm{H}_{2} \mathrm{O}\right)$. A clear demarcation is seen between the two base materials in the weld zone, and it is free of internal defects (Figure 4). The microstructures of $6061 \mathrm{~T} 6$ base material and joints made by friction stir welding of 6061T6-6061T6 (similar materials) sheets are shown in Figure 5. The average grain sizes were measured by intercept method using optical microscope. The base material is characterized by equiaxed initial grains with an average grain size of $25-30 \mu \mathrm{m}$ (Figure 5(a)). Figure 5(b) shows the dynamically recrystallized grains in weld region and the grain size variations from centre to $7 \mathrm{~mm}$ in the width (or transverse) direction a particular FS welding case. It is observed that the average grain size at different weld widths, say from centre to $4 \mathrm{~mm}$ to $7 \mathrm{~mm}$, are (i) $9.23 \mu \mathrm{m}$, $11.63 \mu \mathrm{m}$, and $24.05 \mu \mathrm{m}$, respectively, for a FSW condition with shoulder diameter: $15 \mathrm{~mm}$, rotational speed: $1500 \mathrm{rpm}$, and welding speed: $100 \mathrm{~mm} / \mathrm{min}$ (Figure 5(b)). As compared to the base material, the fine grains are present at the weld zone, and the grain size increases from the centre to offset locations. The larger grain size at the centre of weld is mainly due to the high strain-rate and temperature that exists at that location, which decreases when moved away from the centre.

\subsection{Influence of Shoulder Diameter on Springback for Dissim-} ilar Grade Combination. It is known that, in pure bending, the springback increases with increase in strength, decrease in Young's modulus, increase in yield strength to elastic modulus ratio [21], and decrease in strain hardening exponent, though there are other properties like material thickness, bent radius, working temperature, and so forth that affects the springback. Mori et al. [22] studied the springback of ultrahigh strength steel sheets in bending under controlled conditions using a CNC servo press. They have showed that the springback difference from the punch angle increases considerably with increase in tensile strength to Young's modulus ratio. The effect of sheet strain hardening exponent (n) on springback can be understood from the work of Huang and Leu [23]. It is shown through analytical modelling that, with increasing " $n$ " value of the sheet, springback angle 


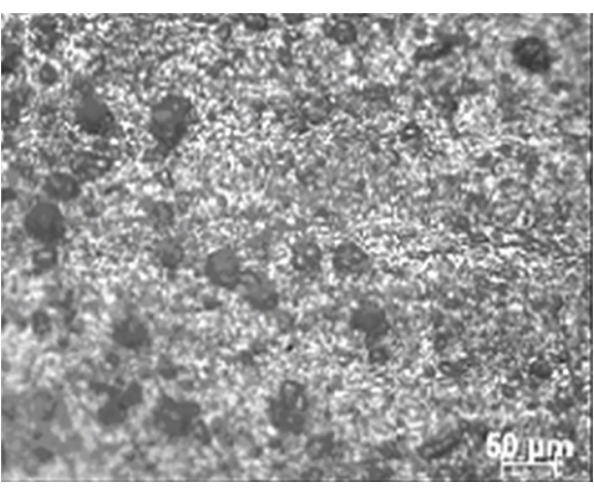

(a)

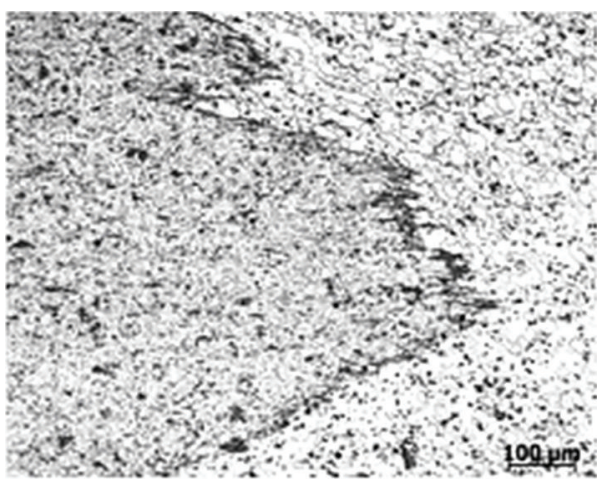

(c)

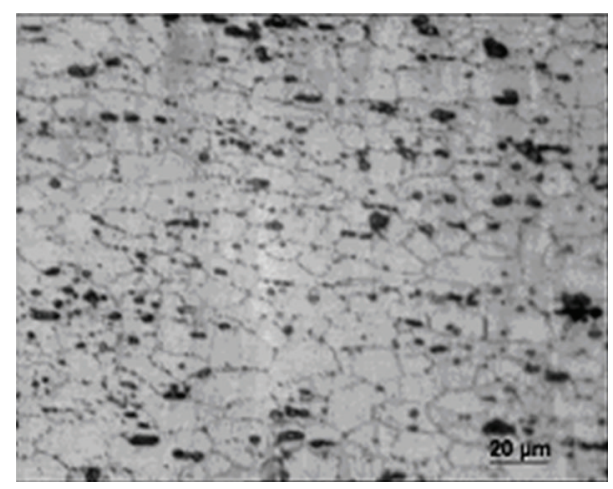

(b)

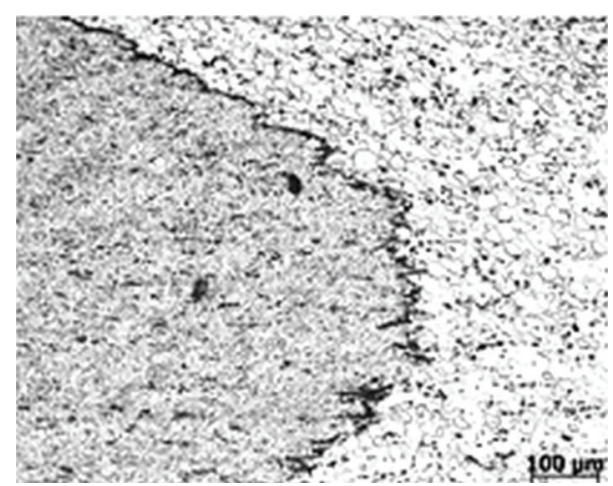

(d)

Figure 4: Microstructures of (a) 5052H32 base material, (b) $6061 \mathrm{~T} 6$ base material, (c) weld zone constituting FS welded sheets made of 5052H32-6061T6 at the welding condition: shoulder diameter: $18 \mathrm{~mm}$; welding speed: $80 \mathrm{~mm} / \mathrm{min}$; rotational speed: $700 \mathrm{rpm}$, and (d) weld zone constituting FS welded sheets made of 5052H32-6061T6 at the welding condition: shoulder diameter; $18 \mathrm{~mm}$; welding speed: $100 \mathrm{~mm} / \mathrm{min}$; rotational speed; $800 \mathrm{rpm}$.

TABLE 3: Springback angles of base materials (reference die angle: $\left.59.2^{\circ}\right)$.

\begin{tabular}{lcc}
\hline \multirow{2}{*}{ Base material grade } & \multicolumn{2}{c}{ Springback angle } \\
& Near radius & Far from radius \\
\hline $5052 \mathrm{H} 32$ & $66.94^{\circ} \pm 0.12^{\circ}$ & $60.58^{\circ} \pm 0.6^{\circ}$ \\
$6061 \mathrm{~T} 6$ & $76.86^{\circ} \pm 0.9^{\circ}$ & $74.76^{\circ} \pm 0.8^{\circ}$ \\
\hline
\end{tabular}

decreases slightly. Murata et al. [24] have shown that during press bending the springback decreases considerably between hardening values of 0.1 and 0.4 , after which the variation is minor.

The springback angles of unwelded base materials, 5052H32 and 6061T6, are presented in Table 3. The data was obtained from three trials to check the repeatability. It is seen that $6061 \mathrm{~T} 6$ base material shows more springback as compared to $5052 \mathrm{H} 32$, because of larger yield strength and smaller strain hardening exponent as given in Tables 1 and 2 .

The influence of shoulder diameter on springback angle for different rotational speed and welding speed combinations is shown in Figure 6. Though there are 27 set of experiments, only selected results are shown for discussion. It is observed that with increase in shoulder diameter from $12 \mathrm{~mm}$ to $16 \mathrm{~mm}$, the springback angle of FS welded sheets decreases considerably. The angles near radius and far from radius show the same trend. The change in springback has been related to the change in weld zone properties like yield strength, elastic modulus, yield strength to elastic modulus ratio, and strain hardening exponent at different welding conditions. The weld zone properties at different welding conditions (like shoulder diameter, welding speed, and rotational speed) were evaluated through tensile tests of FS samples containing just the weld zone. The subsize samples were made of weld zone, such that the gauge region contains just the weld zone. The tensile tests were performed at a cross-head speed of $1 \mathrm{~mm} / \mathrm{min}$ at room temperature. The weld zone properties like yield strength, elastic modulus, and strain hardening exponent were evaluated as per established methods from engineering and true stress-strain behaviour. The thickness of weld zone with respect to base material is also important in deciding the springback. It was observed that weld zone thickness is almost same (about $2.02 \mathrm{~mm}$ ) as that of base material $(2.1 \mathrm{~mm})$, and hence the difference is neglected.

It is observed from Figures 7(a)-7(d) that, with increase in shoulder diameter, the weld yield strength decreases, the weld Young's modulus increases, the yield strength to elastic modulus ratio decreases, and weld " $n$ " value increases. Because of the properties variation, the overall springback of welded sheets decreases with increase in shoulder diameter, 


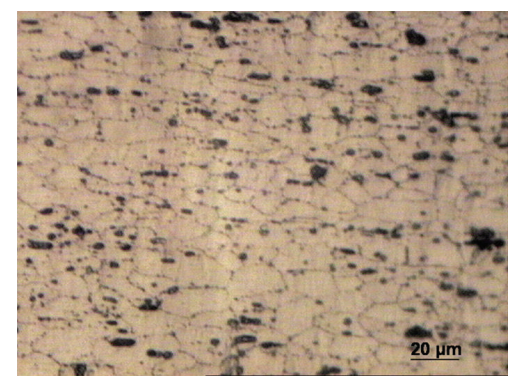

(a) $6061 \mathrm{~T} 6$ base material

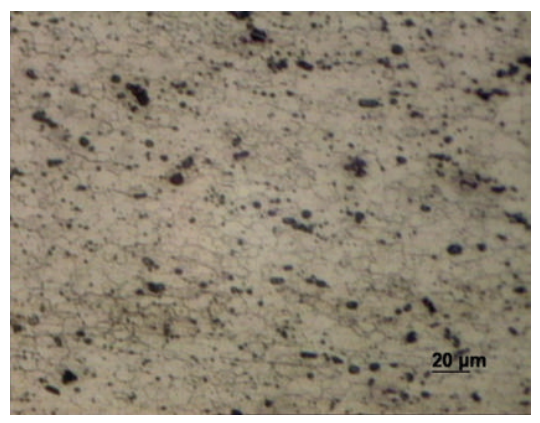

Centre

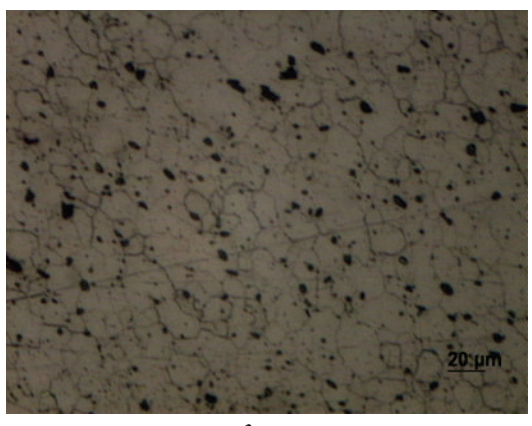

$4 \mathrm{~mm}$ from centre

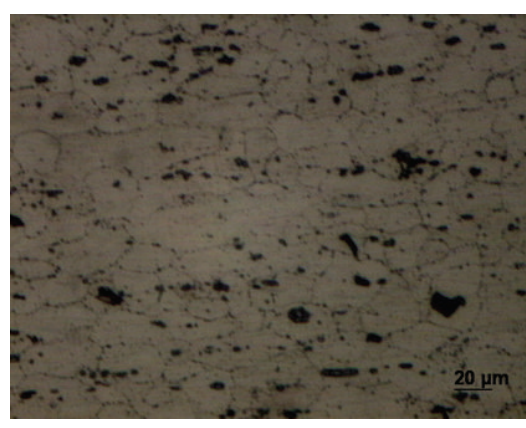

$7 \mathrm{~mm}$ from centre

(b) For FSW condition: shoulder diameter: $15 \mathrm{~mm}$; rotational speed: $1500 \mathrm{rpm}$; welding speed: $100 \mathrm{~mm} / \mathrm{min}$

FIGURE 5: Microstructures of (a) 6061T6 base material and (b) friction stir welded sheets made of 6061T6-6061T6 at one particular welding condition.

as the base materials are common. The relation between the weld zone properties and the overall springback of FSW sheet is in accordance with the available results for unwelded sheet materials [21-24].

Though the weld Young's modulus behaves in an opposite manner in a few cases like for rotational speed $=600 \mathrm{rpm}$, welding speed $=100 \mathrm{~mm} / \mathrm{min}$, rotational speed $=800 \mathrm{rpm}$, and welding speed $=80 \mathrm{~mm} / \mathrm{min}$ in Figure $7(\mathrm{~b})$, the yield strength to elastic modulus ratio shows the direct relation with springback angle (Figure $7(\mathrm{c})$ ).

The springback angles of base materials are also shown in Figure 6 for reference. Since FS welded sheet is a combination of $6061 \mathrm{~T} 6$ and $5052 \mathrm{H} 32$ base materials, its springback is in-between that of base material springback for both near to radius and far from radius cases. This is true for all the FS welding parameters combination. This indicates that the FS welded sheet has better springback performance as compared to $6061 \mathrm{~T} 6$ base material, but inferior to $5052 \mathrm{H} 32$ base material. It can also be said from the results that, for reduced springback, a larger shoulder diameter is preferred, as the weld zone exhibits lower yield strength, higher elastic modulus, lower yield strength to elastic modulus ratio, and higher strain hardening exponent, at this shoulder diameter.

3.3. Influence of Rotational Speed on Springback for Dissimilar Grade Combination. The effect of rotational speed on the springback angle is shown in Figure 8. With increase in rotational speed from 600 to $800 \mathrm{rpm}$, the springback decreases considerably in most of the cases, while in some cases, a minor variation is seen. The angles near radius and

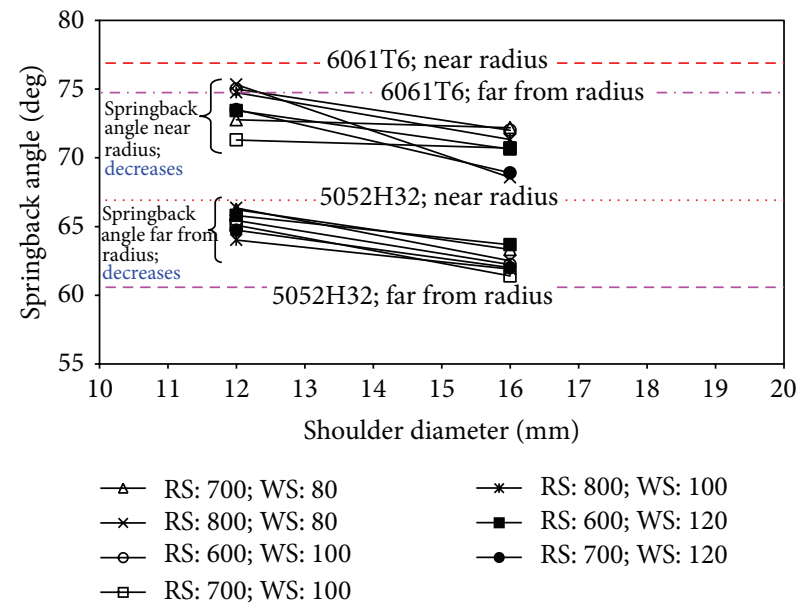

FIGURE 6: Influence of shoulder diameter on springback angle for dissimilar grade combination (reference die angle: $59.2^{\circ}$ ); RS: rotational speed (in $\mathrm{rpm}$ ); WS: welding speed (in $\mathrm{mm} / \mathrm{min}$ ).

far from radius show same pattern of variation. The decrease in springback of the whole FS welded sheet is substantiated with decrease in weld yield strength, increase in weld elastic modulus, decrease in yield strength to elastic modulus ratio, and increase in strain hardening exponent (Figures 9(a)$9(\mathrm{~d})$ ), which is agreeing with the understanding presented in the literature [21-24].

Though the weld elastic modulus (Figure 9(b)) is expected to increase with increase in rotational speed, it 


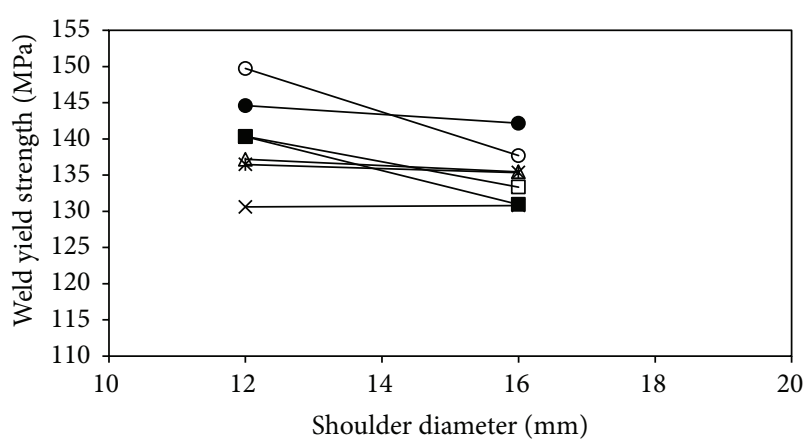

(a)

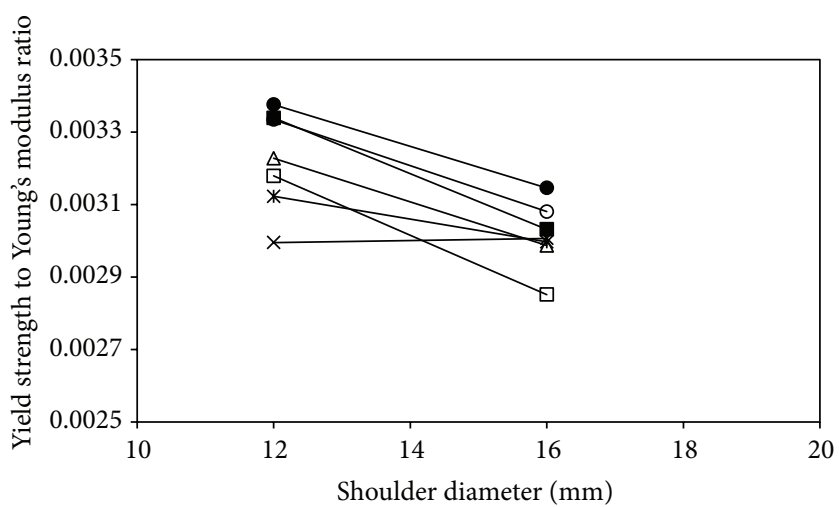

(c)

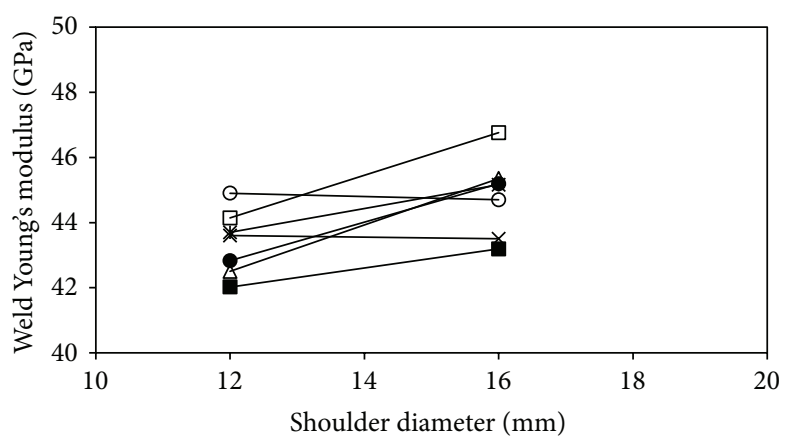

(b)

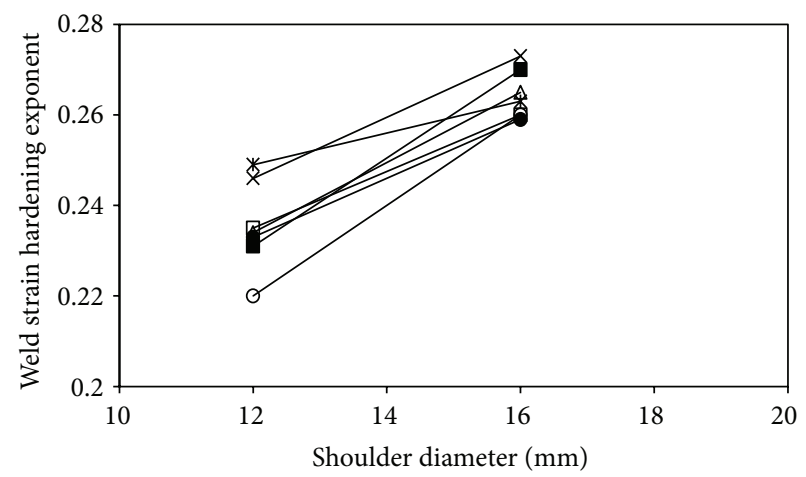

*- RS: 800; WS: 100

* RS: 800; WS: $80 \rightarrow$ RS: 600; WS: 120

- - RS: 600; WS: 100

七 RS: 700; WS: 100

(d)

FiguRE 7: Influence of shoulder diameter on (a) weld yield strength, (b) weld Young's modulus, (c) yield strength to Young's modulus ratio, and (d) weld strain hardening exponent; RS: rotational speed (in rpm); WS: welding speed (in $\mathrm{mm} / \mathrm{min}$ ).

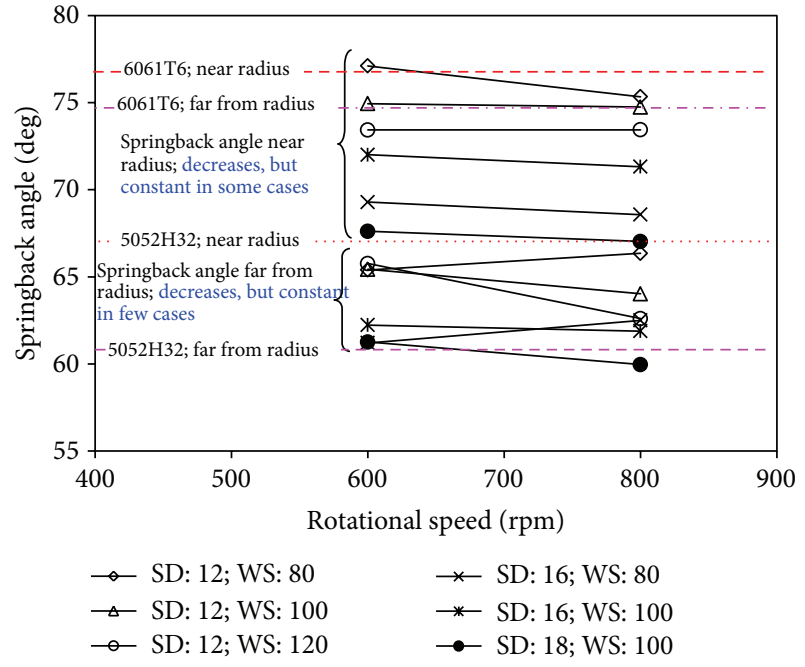

FIGURE 8: Influence of rotational speed on springback angle for dissimilar grade combination (reference die angle: $59.2^{\circ}$ ); $\mathrm{SD}$ : shoulder diameter (in $\mathrm{mm}$ ); WS: welding speed (in $\mathrm{mm} / \mathrm{min}$ ). shows a mixed type of variation. Hence the change in yield strength to elastic modulus ratio is monitored (Figure 9(c)) and the variation is consistent with the available literature results. Even in this case, the FS welded sheet has better springback performance as compared to $6061 \mathrm{~T} 6$ base material, but inferior to $5052 \mathrm{H} 32$ base material. It can be concluded from the results that, for reduced springback, a higher rotational speed is preferred, as the weld zone exhibits lower yield strength, lower yield strength to elastic modulus ratio, and higher strain hardening exponent, at this level.

\subsection{Influence of Welding Speed on Springback for Dissimilar} Grade Combination. With increase in welding speed from 100 to $120 \mathrm{~mm} / \mathrm{min}$, the springback angle decreases considerably in the location near to radius (Figure 10). But the springback angle far from radius is almost constant, though some decrease occurs in a few cases. The decrease in springback is due to the decrease in weld yield strength, decrease in yield strength to elastic modulus ratio, and increase in strain hardening exponent as presented in Figures 11(a)-11(d). The correlation agrees well with the available literature. The 


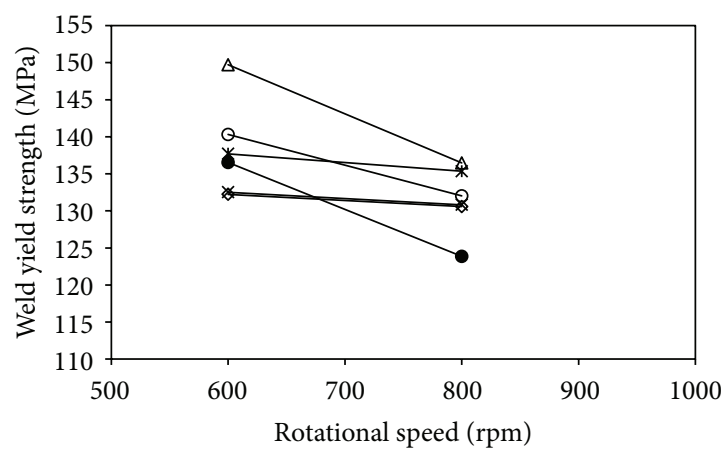

(a)

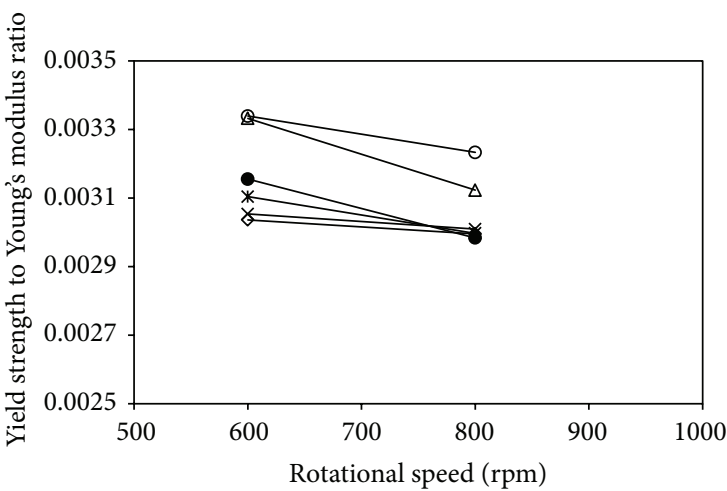

$\begin{array}{ll}\rightarrow \text { SD: } 12 \text {; WS: } 80 & * \text { SD: } 16 \text {; WS: } 80 \\ \rightarrow \text { SD: } 12 \text {; WS: } 100 & \text { * SD: } 16 \text {; WS: } 100 \\ \rightarrow \text { SD: } 12 \text {; WS: } 120 & \rightarrow-\text { SD: } 18 \text {; WS: } 100\end{array}$

(c)

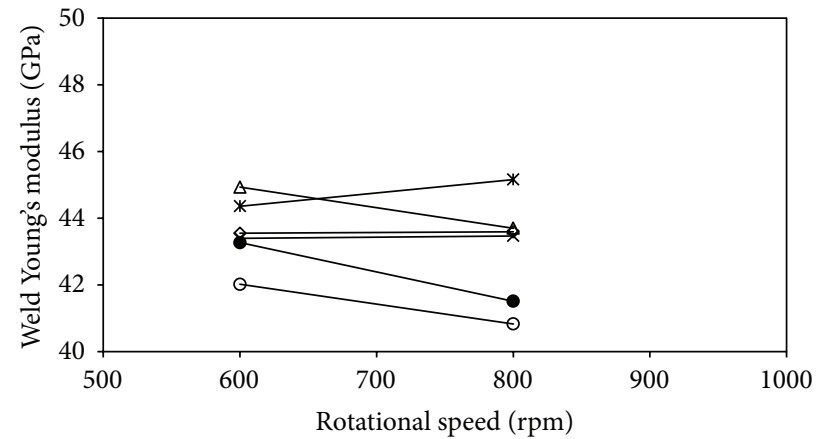

(b)

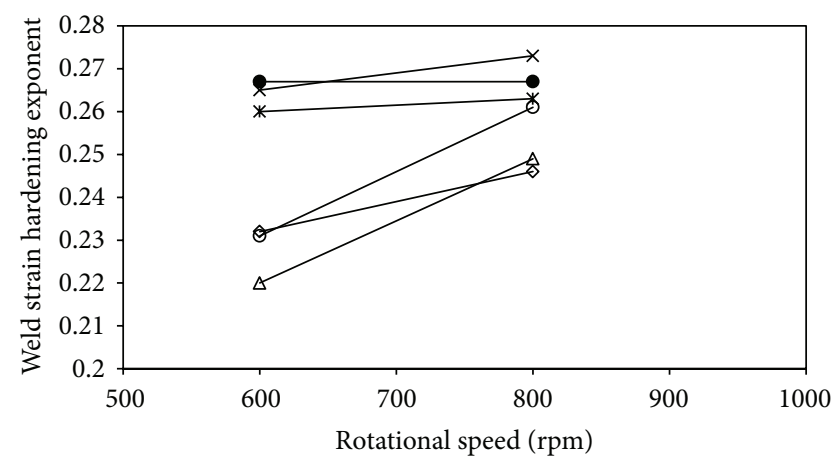

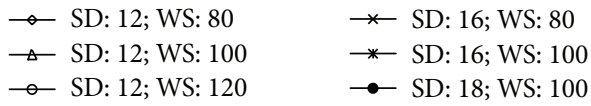

(d)

FIGURE 9: Influence of rotational speed on (a) weld yield strength, (b) weld Young's modulus, (c) yield strength to Young's modulus ratio, and (d) weld strain hardening exponent; SD: shoulder diameter (in $\mathrm{mm}$ ); WS: welding speed (in $\mathrm{mm} / \mathrm{min}$ ).

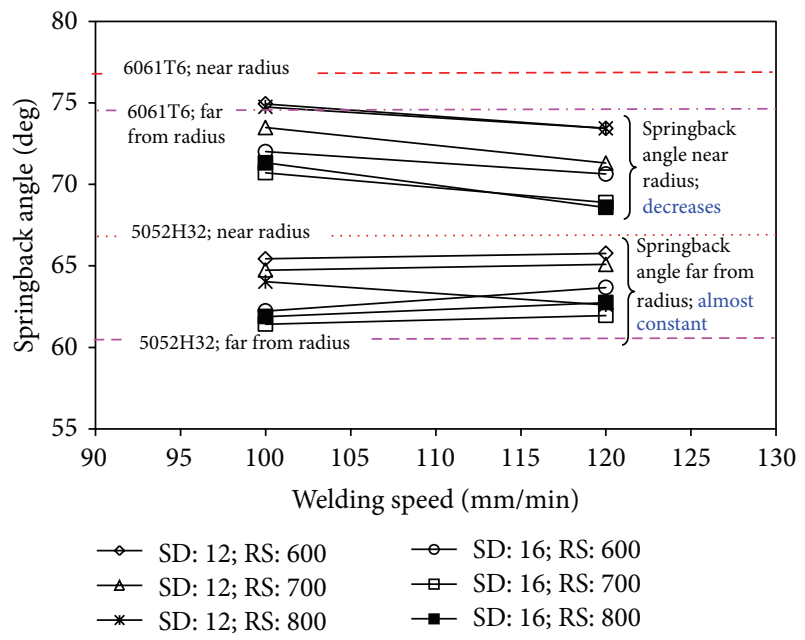

FIGURE 10: Influence of welding speed on springback angle for dissimilar grade combination (reference die angle: $59.2^{\circ}$ ); SD: shoulder diameter (in $\mathrm{mm}$ ); RS: rotational speed (in rpm).

relation between weld elastic modulus and springback is not clear, as in some cases it decreases, but increase in elastic modulus is expected. With respect to the welding speed effect, the FS welded sheet has better springback performance as compared to $6061 \mathrm{~T} 6$ base material, but inferior to $5052 \mathrm{H} 32$ base material. For reduced springback, a higher welding speed is favoured, as the weld zone exhibits lower yield strength, lower yield strength to elastic modulus ratio, and higher strain hardening exponent, at this level.

3.5. Influence of Shoulder Diameter on Springback for Similar Grade Combination. The effect of shoulder diameter, rotational speed, and welding speed on springback angle is shown for punch nose radius of $3.15 \mathrm{~mm}$ only. The influence of shoulder diameter on the springback of FS welded sheets made of similar grade is shown in Figure 12. The springback decreases considerably with increase in shoulder diameter. This is true for angle near to radius and far from radius. The behaviour coincides with the behaviour of dissimilar grade combination (Figure 6). The springback change is substantiated with the change in weld zone properties like yield strength to Young's modulus ratio and strain hardening exponent only (Figures 13(a) and 13(b)). Since the combined effect of yield strength and Young's modulus is present in yield strength to Young's modulus ratio, the properties are not shown separately. It is observed that with increase 


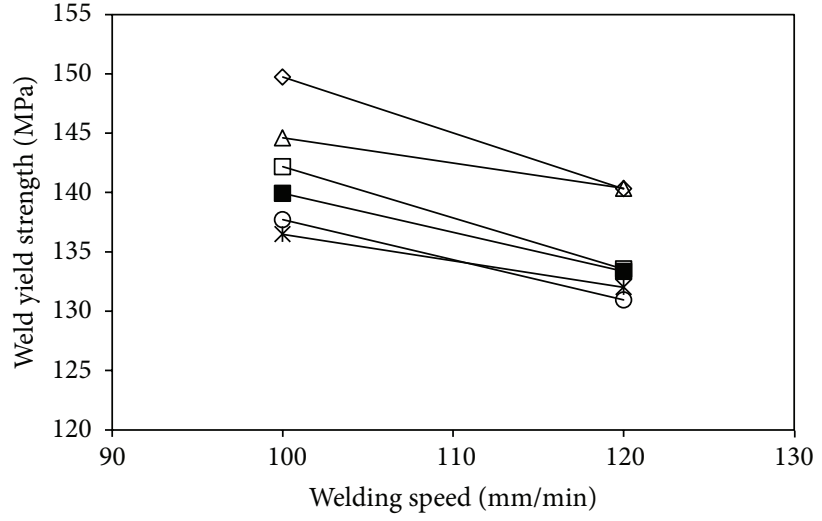

(a)

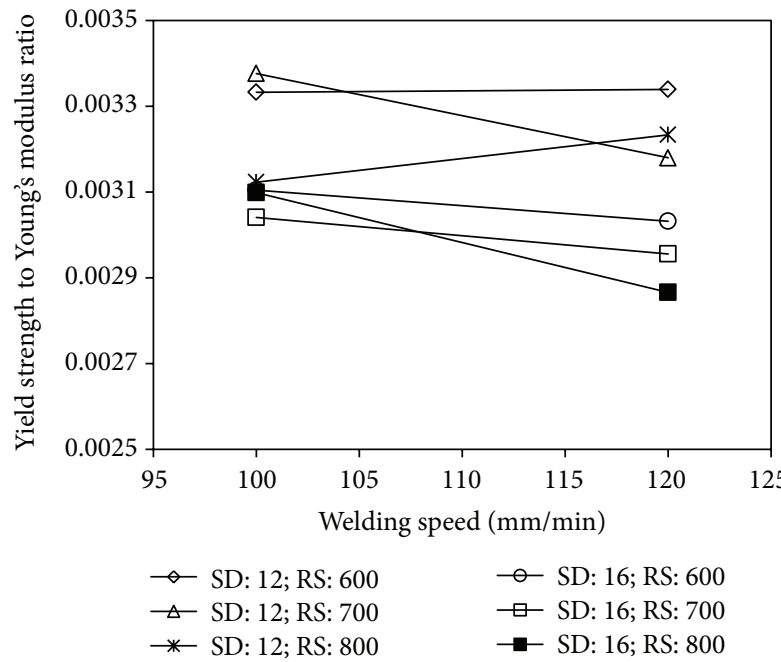

(c)

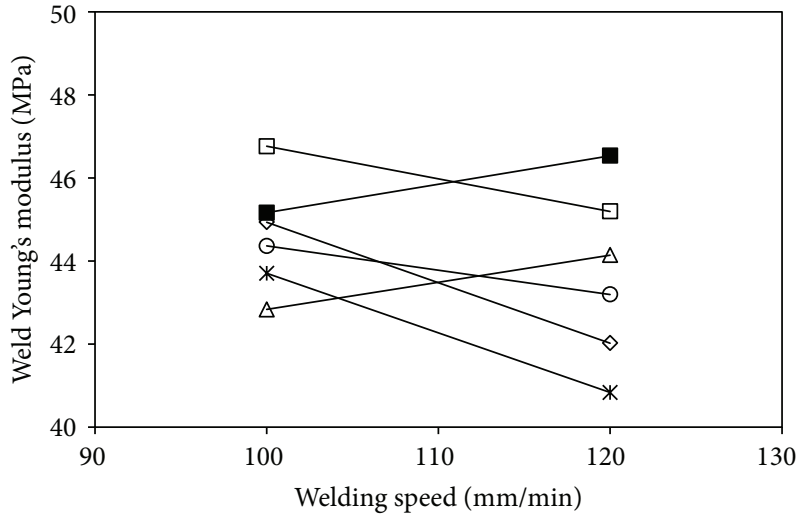

(b)
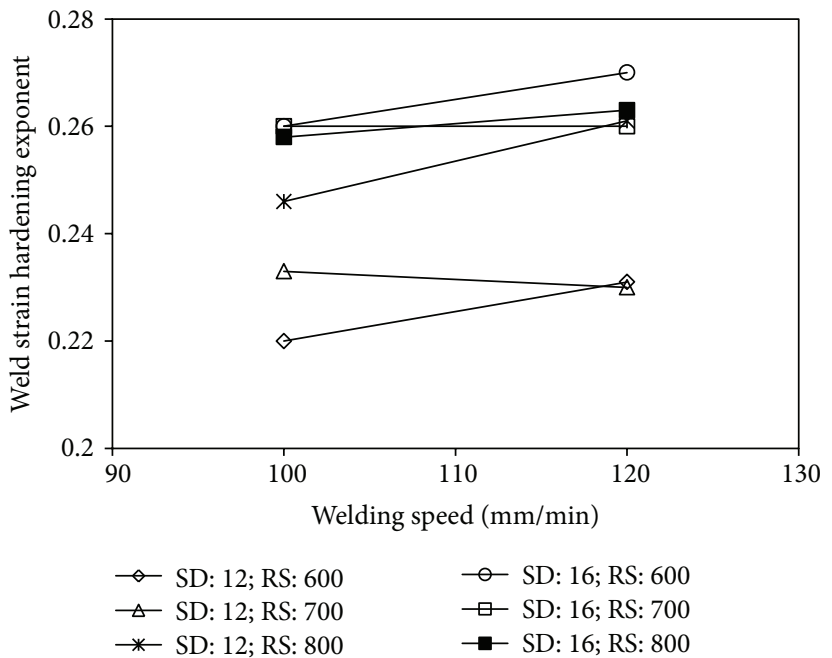

(d)

FiguRE 11: Influence of welding speed on (a) weld yield strength, (b) weld Young's modulus, (c) yield strength to Young's modulus ratio, and (d) weld strain hardening exponent; SD: shoulder diameter (in mm); RS: rotational speed (in rpm).

in shoulder diameter, both the ratio and strain hardening exponent increase. The increasing trend of yield strength to Young's modulus ratio is unexpected as it has direct relation with springback, and hence it should decrease. The increasing strain hardening exponent and hence the decreasing springback coincide with the literature results. Probably the change in strain hardening exponent is dominating the effect of yield strength to Young's modulus ratio, and the overall springback of welded sheets decreases. It is also observed that the springback performance of FS welded sheets made of 6061T6 grade is better than that of parent material (Figure 12). The performance is better in all the welding conditions. It can be said that for reduced springback of FS welded sheets made of 6061T6, a larger shoulder diameter is favoured.

3.6. Influence of Rotational Speed and Welding Speed on Springback for Similar Grade Combination. The rotational speed has shown positive influence on springback, when it is increased from $1300 \mathrm{rpm}$ to $1400 \mathrm{rpm}$ (Figure 14), though the springback change is insignificant in some cases. The decrease in springback is substantiated with increasing weld strain hardening exponent and decreasing yield strength to Young's modulus ratio (Figures 15(a) and 15(b)). Like in previous cases, the FS welded sheets made of $6061 \mathrm{~T} 6$ grade show a better performance as compared to base materials in all the welding conditions.

The effect of welding speed is to reduce the springback when increased from $90 \mathrm{~mm} / \mathrm{min}$ to $100 \mathrm{~mm} / \mathrm{min}$ (Figure 16). The springback reduction is due to the decrease in yield strength to Young's modulus ratio and increase in weld strain hardening exponent (Figures 17(a) and 17(b)), though the increase in strain hardening exponent is not considerable in some cases. Because of the properties change in the weld zone, the welded sheets show better springback performance as compared to unwelded base material (6061T6) at any welding condition (Figure 16). A higher rotational speed and higher welding speed are required for reduced springback.

3.7. Influence of Punch Nose Radius on Springback (Dissimilar Material Combination). The parameters like punch nose 


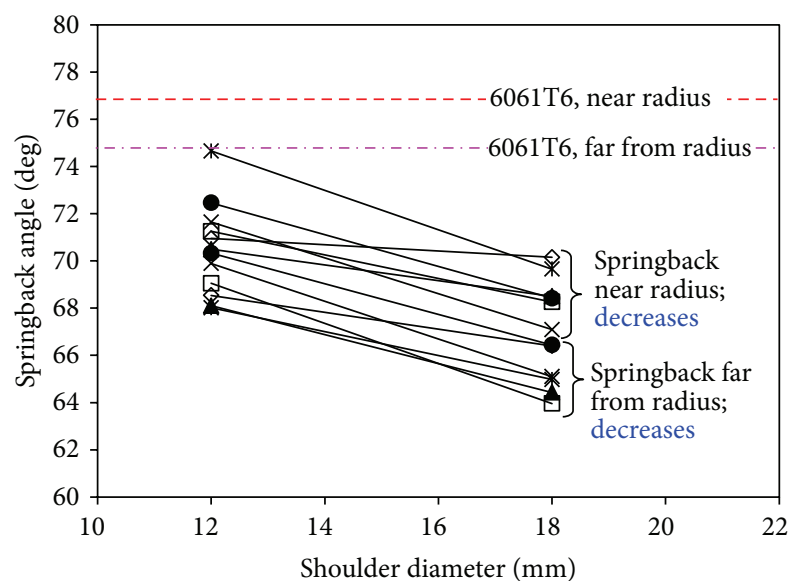

$\multimap$ RS: 1300; WS: 90; PD: $1.9 \rightarrow$ RS: 1400; WS: 90; PD: 1.85 $\rightarrow$ RS: 1300; WS: 100; PD: 1.9 — RS: 1400; WS: 100; PD: 1.9

$\multimap$ RS: 1300; WS: 100; PD: $1.85 \multimap$ RS: 1400; WS: 100; PD: 1.85

FIGURE 12: Influence of shoulder diameter on the springback angle for similar grade combination (reference die angle: $59.2^{\circ}$ ); RS: rotational speed (in $\mathrm{rpm}$ ), WS: welding speed (in $\mathrm{mm} / \mathrm{min}$ ), and PD: plunge depth (in $\mathrm{mm}$ ).

radius, die corner radius, interface friction between the tools, and so forth affect the springback during V-bending in a compounding fashion. For example, the work done by Huang and Leu [23] showed that, with increase in punch nose radius from $3 \mathrm{~mm}$ to $6 \mathrm{~mm}$, and the die radius from $6 \mathrm{~mm}$ to $15 \mathrm{~mm}$, the springback angle has increased. The springback reduction is mainly due to the increased plastic deformation levels of sheets at the localised region when punch nose/die radius is reduced. The same has been observed by Kim et al. [25] on a fibre metal laminate in the brake forming process. In present work, the effect of punch nose radius, $0.7 \mathrm{~mm}$ and $3.15 \mathrm{~mm}$, on the springback of FS welded sheets has been briefly reported. It is understood from Figures 18(a) and 18(b) that a punch with lower nose radius has lesser springback as compared to a punch with larger nose radius. The springback angles near radius and far from radius follow the same pattern, except in one or two cases. This is due to the larger plastic deformation levels achieved during bending of FS welded sheets using a punch with lower nose radius which decreases the relative effect of elastic deformation.

Just to summarize the present work, the chosen welding parameters, shoulder diameter, rotational speed, and welding speed, affect the springback of friction stir welding sheets significantly, in most of the cases. The change in springback is due to the change in weld zone properties like yield strength, elastic modulus, yield strength to elastic modulus ratio, and strain hardening exponent during friction stir welding. The welding conditions that provide a lower yield strength, higher elastic modulus, lower yield strength to elastic modulus ratio, and higher strain hardening exponent are preferred, as they exhibit reduced springback. The better performance of FS welded sheets in comparison with $6 \mathrm{xxx}$ base material should be noted. In the case of similar Al grade combination (6061T6-6061T6), the weld strength reduction
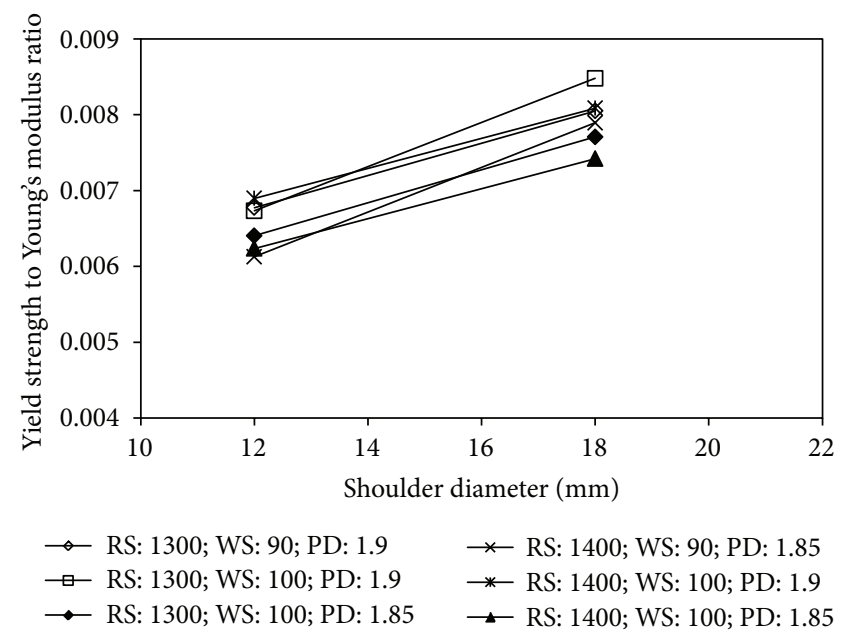

(a)

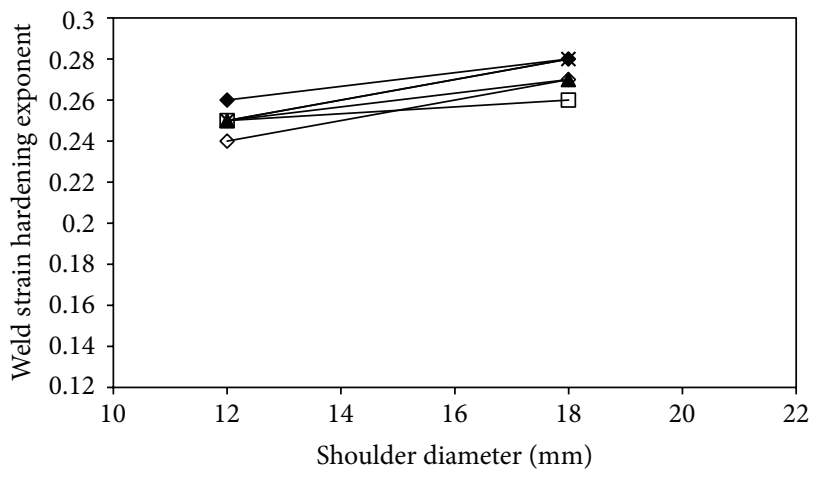

$\multimap$ RS: 1300; WS: 90; PD: $1.9 \quad \longrightarrow$ RS: 1400; WS: 90; PD: 1.85

$\rightarrow$ RS: 1300; WS: 100; PD: 1.9 — RS: 1400; WS: 100; PD: 1.9

$\multimap$ RS: 1300; WS: 100; PD: $1.85 \multimap$ RS: 1400; WS: 100; PD: 1.85

(b)

FIGURE 13: Influence of shoulder diameter on (a) yield strength to Young's modulus ratio, (b) weld strain hardening exponent; RS: rotational speed (in rpm), WS: welding speed (in $\mathrm{mm} / \mathrm{min}$ ), and PD: plunge depth (in $\mathrm{mm}$ ).

is related to coarsening and dissolution of strengthening precipitates during the thermal cycle of the FSW $[1,26]$, while the improvement in weld strain hardening exponent is due to the significant reduction of dislocation density as compared to base material [27]. Because of these properties change, the overall strength of FS welded sheets has reduced, and strain hardening exponent has increased, resulting in reduced springback, as compared to springback of 6061T6 base material. In the case of FS processed sheets made of $5052 \mathrm{H} 32$ grade, the improvement in springback during unconstrained bending is already reported by Park et al. [13]. This is due to the reduction in yield strength and improvement in strain hardening exponent of weld zone because of reduction in dislocation density in the weld zone during the thermal cycle. Now if both the base materials, $6061 \mathrm{~T} 6$ and $5052 \mathrm{H} 32$, are friction stir welded to make tailor welded sheets, then the effect is to reduce the weld strength and improve the strain hardening exponent as depicted 


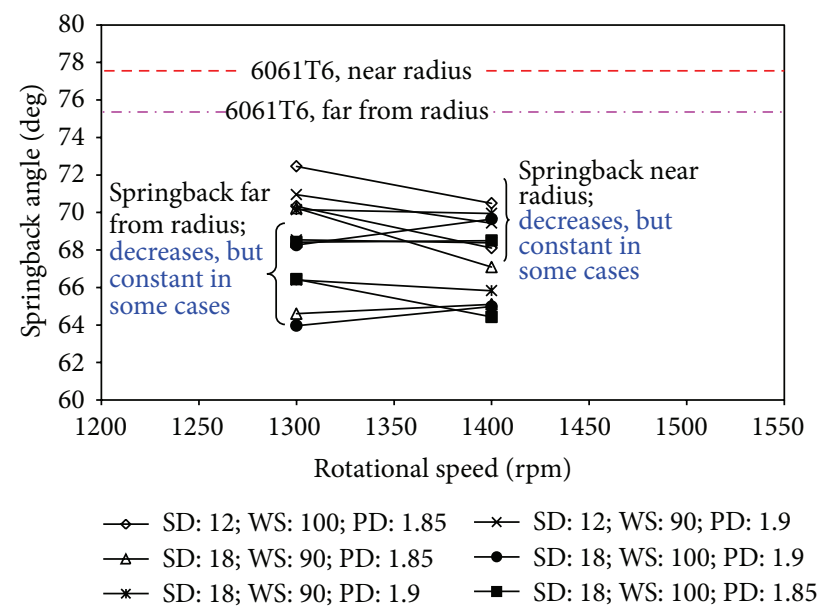

FIGURE 14: Influence of rotational speed on the springback angle for similar grade combination (reference die angle: $59.2^{\circ}$ ); SD: shoulder diameter (in $\mathrm{mm}$ ), WS: welding speed (in $\mathrm{mm} / \mathrm{min}$ ), and PD: plunge depth (in $\mathrm{mm}$ ).

in the previous figures, because of which the springback of dissimilar Al grade combination (6061T6-5052H32) is reduced. The amount of springback reduction depends on the overriding capacity of phenomenon happening in 6061T6 and $5052 \mathrm{H} 32$ grades during FSW, and hence the springback of welded sheets made of 6061T6-5052H32 combination is inbetween that of two base materials (Figures 6, 8 and 10).

Another important fact to be noted is on proper tailoring of base materials for reduced springback. Since both similar and dissimilar Al grade combination showed reduced springback performance as compared to unwelded 6061T6 grade, one has to compare the springback of defect free welded sheets under same welding conditions to choose proper tailoring of base materials. Moreover, the optimized higher levels of shoulder diameter, rotational speed, and welding speed, for reduced springback in the present work, may not be suitable for other formability parameters like forming limit. For instance, Ramulu et al. [17] have demonstrated that, at higher welding speed of $100 \mathrm{~mm} / \mathrm{min}$, the forming limit of FS welded sheets made of 6061T6 grade is less when compared to the forming limit at a lower level, $90 \mathrm{~mm} / \mathrm{min}$, which is not desirable from formability point of view. Hence the final sheet forming design depends not only on the welding conditions, but also on the application of friction stir welded sheet components.

\section{Conclusions}

The main aim of the present work is to study the influence of shoulder diameter, rotational speed, and welding speed on the springback of friction stir welded sheets made of dissimilar (6061T6-5052H32) and similar (6061T6-6061T6) grades during V-bending. The following conclusions are drawn from the results.
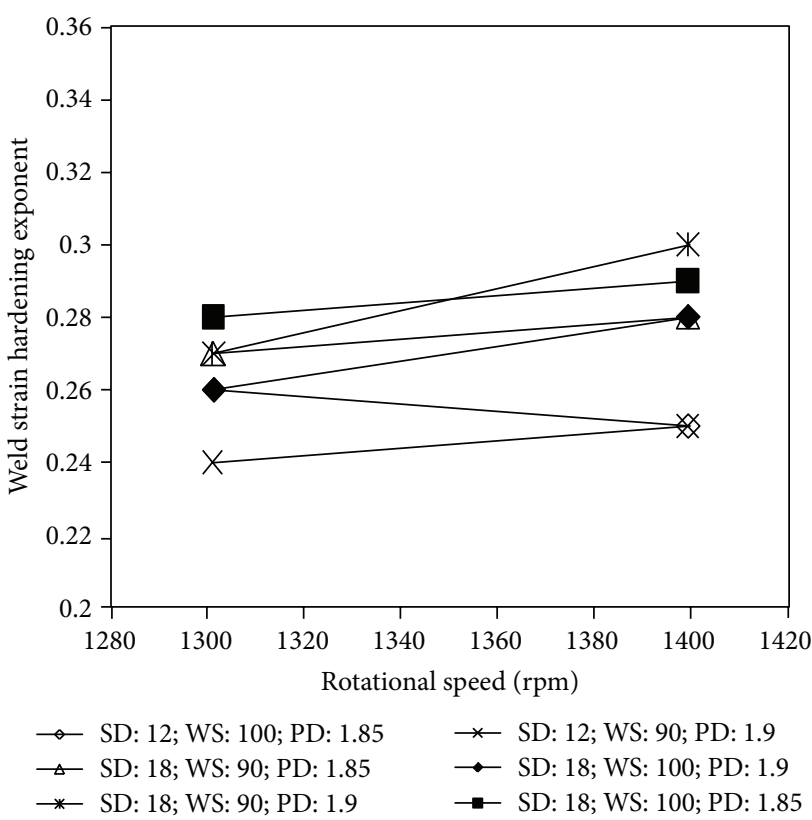

(a)

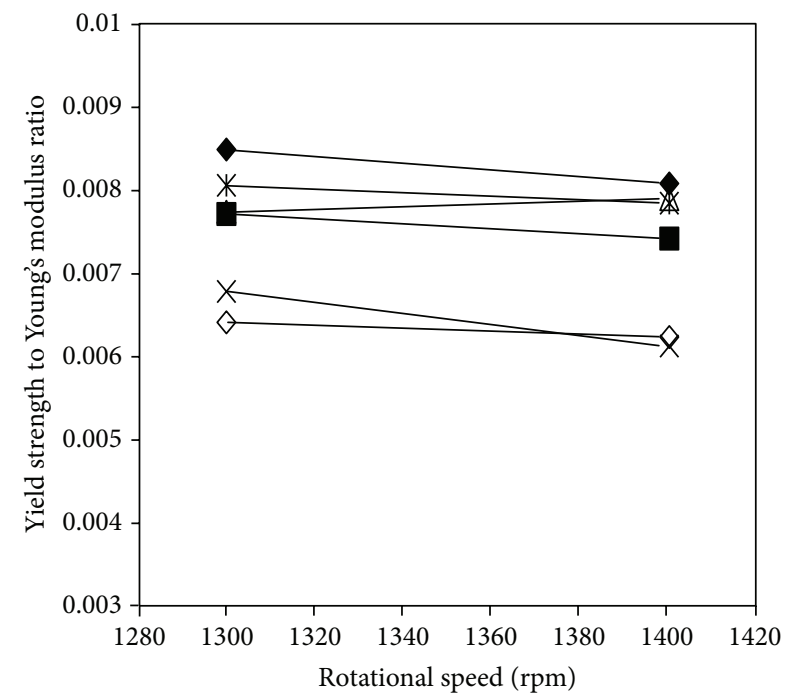

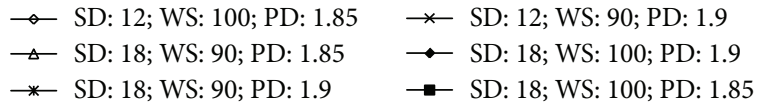

(b)

FIGURE 15: Influence of rotational speed on (a) weld strain hardening exponent, (b) yield strength to Young's modulus ratio; SD: shoulder diameter (in $\mathrm{mm}$ ), WS: welding speed (in $\mathrm{mm} / \mathrm{min}$ ), and PD: plunge depth (in $\mathrm{mm}$ ).

(i) With increase in shoulder diameter, rotational speed, and welding speed, within chosen levels, the springback of friction stir welded sheets has decreased. This is true for both dissimilar and similar Al grade combinations.

(ii) The change in weld zone mechanical properties like yield strength, Young's modulus, yield strength to 


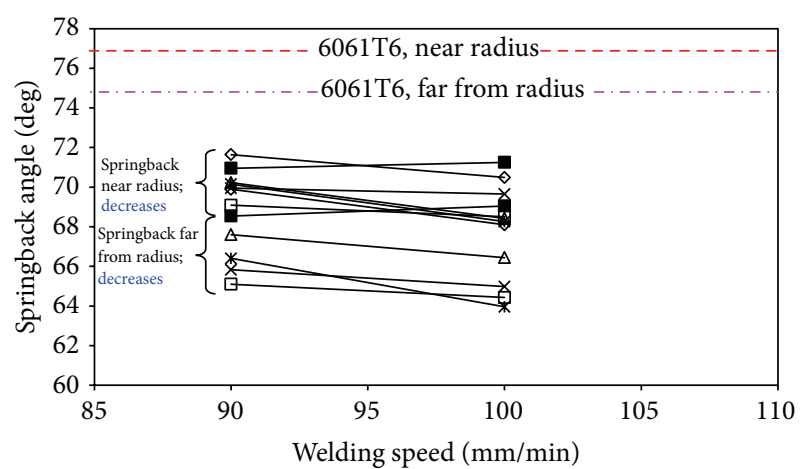

$\rightarrow$ SD: 12; RS: 1400; PD: 1.85

$\rightarrow$ SD: 18 ; RS: 1400; PD: 1.85

* SD: 18 ; RS: 1300; PD: 1.9

$\rightarrow$ SD: 18 ; RS: 1400 ; PD: 1.9

$\triangle$ SD: 18; RS: 1300; PD: 1.85

$\rightarrow$ SD: 12 ; RS: 1300; PD: 1.9

FIGURE 16: Influence of welding speed on the springback angle for similar grade combination (reference die angle: $59.2^{\circ}$ ); SD: shoulder diameter (in $\mathrm{mm}$ ), RS: rotational speed (in rpm), and PD: plunge depth (in $\mathrm{mm}$ ).

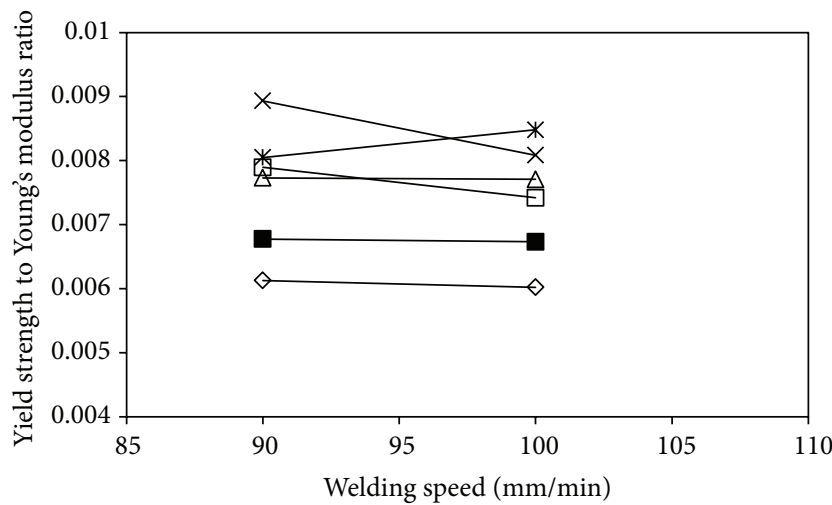

$\multimap$ SD: 12; RS: 1400; PD: 1.85

$\rightarrow$ SD: 18 ; RS: 1400 ; PD: 1.85

* SD: 18 ; RS: 1300; PD: 1.9

$\triangle$ SD: 18 ; RS: 1300; PD: 1.85

* SD: 18 ; RS: 1400 ; PD: 1.9

$\rightarrow$ SD: 12 ; RS: 1300; PD: 1.9

(a)

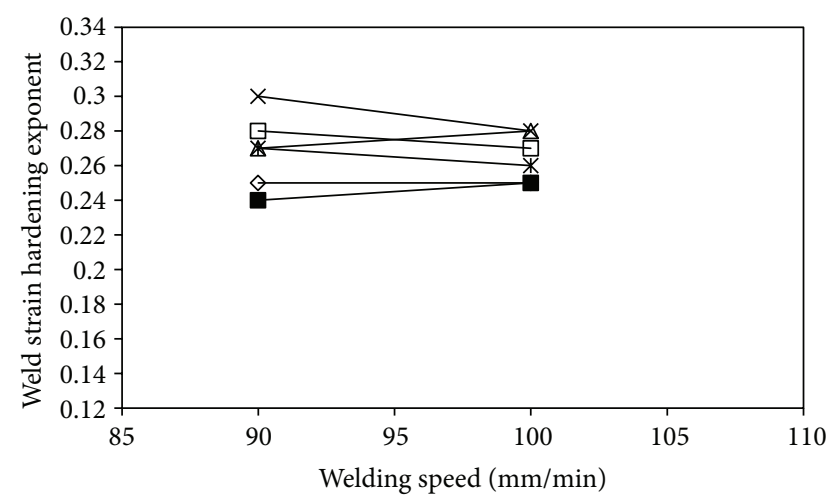

$\rightarrow$ SD: 12 ; RS: 1400 ; PD: $1.85 \rightarrow$ SD: 18 ; RS: 1300 ; PD: 1.9
$\rightarrow$ SD: 18 ; RS: 1400; PD: $1.85 \rightarrow$ SD: 18 ; RS: 1400 ; PD: 1.9
$\rightarrow$ SD: 18 ; RS: 1300; PD: $1.85 \rightarrow$ SD: 12 ; RS: 1300; PD: 1.9

(b)

FIGURE 17: Influence of welding speed on (a) yield strength to Young's modulus ratio, (b) weld strain hardening exponent; SD: shoulder diameter (in $\mathrm{mm}$ ), RS: rotational speed (in $\mathrm{rpm}$ ), and PD: plunge depth (in $\mathrm{mm}$ ).

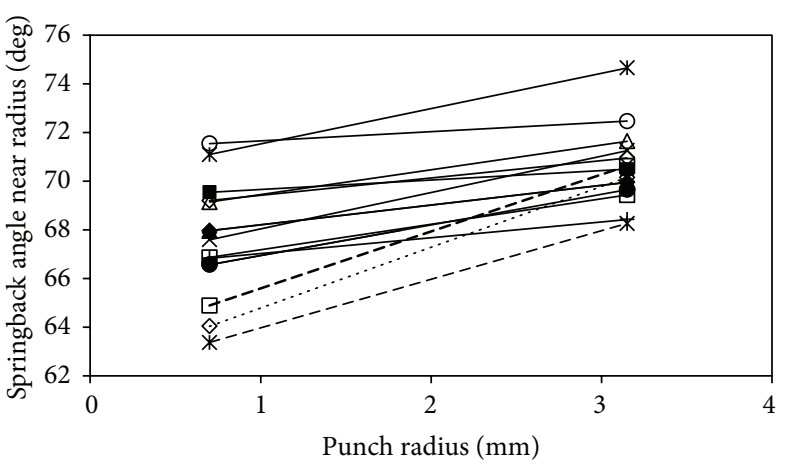

(a)

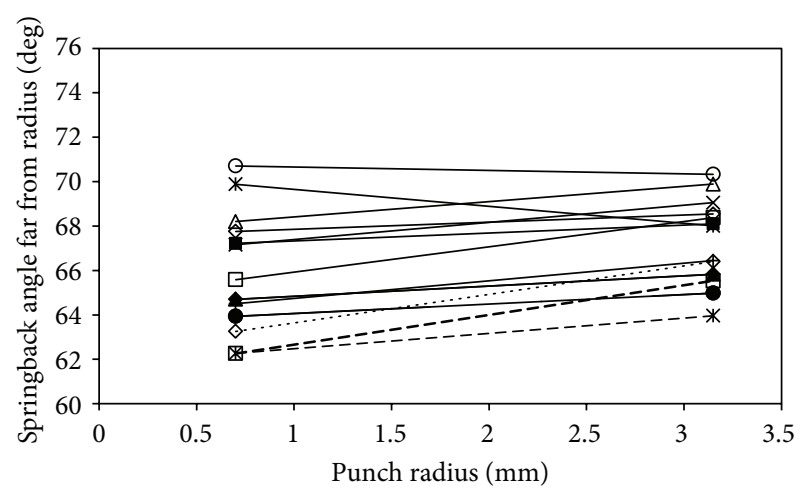

(b)

FIGURE 18: Influence of punch nose radius on springback of friction stir welded sheets made of dissimilar materials.

Young's modulus ratio, and strain hardening exponent with respect to welding conditions is responsible for springback reduction. The relation between springback change and properties change agrees well with existing understanding about springback of unwelded sheets.

(iii) The friction stir welded sheets made of dissimilar $\mathrm{Al}$ grades show better springback performance as compared to 6061T6 base material, but inferior to $5052 \mathrm{H} 32$ base material.

(iv) The friction stir welded sheets made of similar $\mathrm{Al}$ grades show better springback performance as compared to $6061 \mathrm{~T} 6$ base material, in all the welding conditions.

(v) The springback of friction stir welded sheets has increased with increase in punch nose radius. This is due to the larger plastic deformation achieved during bending of welded sheets using a punch with lower nose radius which decreases the relative effect of elastic deformation.

(vi) It has been demonstrated that by proper tailoring of base materials, say $\mathrm{Al}$ grades, by modification of weld zone properties through friction stir welding and by selecting appropriate punch nose radius, the springback of FSW sheets can be reduced considerably. 


\section{Conflict of Interests}

The authors declare that there is no conflict of interests regarding the publication of this paper.

\section{Acknowledgments}

The authors thank Aeronautics Research and Development Board (ARDB), India, for funding the project. The present work is part of the funded project. The authors also thank Dr. Sumitesh Das and Dr. A. N. Bhagat, Tata Steel R \& D, India, for helping them in obtaining the weld microstructures.

\section{References}

[1] R. S. Mishra and Z. Y. Ma, "Friction stir welding and processing," Materials Science and Engineering R: Reports, vol. 50, no. 1-2, pp. 1-78, 2005.

[2] S. L. Semiatin, "Bending of sheet metals," in ASM Handbook on Metal Working: Sheet Forming 14B, pp. 295-305, ASM International, Materials Park, Ohio, USA, 2006.

[3] Y. H. Moon, S. S. Kang, J. R. Cho, and T. G. Kim, "Effect of tool temperature on the reduction of the springback of aluminum sheets," Journal of Materials Processing Technology, vol. 132, no. 1-3, pp. 365-368, 2003.

[4] S.-W. Lee, "A study on the bi-directional springback of sheet metal stamping," Journal of Materials Processing Technology, vol. 167, no. 1, pp. 33-40, 2005.

[5] M. L. Garcia-Romeu, J. Ciurana, and I. Ferrer, "Springback determination of sheet metals in an air bending process based on an experimental work," Journal of Materials Processing Technology, vol. 191, no. 1-3, pp. 174-177, 2007.

[6] R. J. A. de Sousa, J. P. M. Correia, F. J. P. Simoes et al., "Unconstrained springback behavior of Al-Mg-Si sheets for different sitting times," International Journal of Mechanical Sciences, vol. 50, no. 9, pp. 1381-1389, 2008.

[7] R. Grze, P. Y. Manach, H. Laurent, S. Thuillier, and L. F. Menezes, "Influence of the temperature on residual stresses and springback effect in an aluminium alloy," International Journal of Mechanical Sciences, vol. 52, no. 9, pp. 1094-1100, 2010.

[8] J. F. Wang, R. H. Wagoner, W. D. Carden, D. K. Matlock, and F. Barlat, "Creep and anelasticity in the springback of aluminum," International Journal of Plasticity, vol. 20, no. 12, pp. 2209-2232, 2004.

[9] H. Lim, M. G. Lee, J. H. Sung, J. H. Kim, and R. H. Wagoner, "Time-dependent springback of advanced high strength steels," International Journal of Plasticity, vol. 29, no. 1, pp. 42-59, 2012.

[10] J. Yanagimoto and K. Oyamada, "Mechanism of springbackfree bending of high-strength steel sheets under warm forming conditions," CIRP Annals-Manufacturing Technology, vol. 56, no. 1, pp. 265-268, 2007.

[11] L. Wang, G. Huang, H. Zhang, Y. Wang, and L. Yin, "Evolution of springback and neutral layer of AZ31B magnesium alloy Vbending under warm forming conditions," Journal of Materials Processing Technology, vol. 213, no. 6, pp. 844-850, 2013.

[12] H. Y. Yu, "Variation of elastic modulus during plastic deformation and its influence on springback," Materials and Design, vol. 30, no. 3, pp. 846-850, 2009.

[13] S. Park, C. G. Lee, J. Kim, H. N. Han, S.-J. Kim, and K. Chung, "Improvement of formability and spring-back of AA5052H32 sheets based on surface friction stir method," Journal of Engineering Materials and Technology, Transactions of the ASME, vol. 130, no. 4, pp. 0410071-04100710, 2008.

[14] J. Kim, W. Lee, K.-H. Chung et al., "Springback evaluation of friction stir welded TWB automotive sheets," Metals and Materials International, vol. 17, no. 1, pp. 83-98, 2011.

[15] S. Park, C. G. Lee, H. N. Han, N. Ma, and K. Chung, "Surface friction stir method to improve formability and spring-back of AA5052-H32 sheets," International Journal of Material Forming, vol. 1, no. 1, pp. 261-264, 2008.

[16] M. P. Miles, M. W. Mahoney, and C. B. Fuller, "Prediction of bending limits in friction-stir-processed thick plate aluminum," Metallurgical and Materials Transactions A: Physical Metallurgy and Materials Science, vol. 37, no. 2, pp. 399-404, 2006.

[17] P. J. Ramulu, S. V. Kailas, and R. G. Narayanan, "Influence of tool rotation speed and feed rate on the forming limit of friction stir welded AA6061-T6 sheets," Proceedings of the Institution of Mechanical Engineers, Part C: Journal of Mechanical Engineering Science, vol. 227, pp. 520-541, 2013.

[18] A. P. Karafillis and M. C. Boyce, "Tooling and binder design for sheet metal forming processes compensating springback error," International Journal of Machine Tools and Manufacture, vol. 36, no. 4, pp. 503-526, 1996.

[19] W. Gan and R. H. Wagoner, "Die design method for sheet springback," International Journal of Mechanical Sciences, vol. 46, no. 7, pp. 1097-1113, 2004.

[20] M. Kumar, S. V. Kailas, and R. G. Narayanan, "Influence of external weld flash on the in-plane plane-strain formability of friction stir welded sheets," Journal of Strain Analysis for Engineering Design, vol. 48, pp. 376-3385, 2013.

[21] Z. Marciniak, J. L. Duncan, and S. J. Hu, Mechanics of Sheet Metal Forming, Elsevier, New Delhi, India, 1st edition, 2002.

[22] K. Mori, K. Akita, and Y. Abe, "Springback behaviour in bending of ultra-high-strength steel sheets using CNC servo press," International Journal of Machine Tools and Manufacture, vol. 47, no. 2, pp. 321-325, 2007.

[23] Y.-M. Huang and D.-K. Leu, "Effects of process variables on V-die bending process of steel sheet," International Journal of Mechanical Sciences, vol. 40, no. 7, pp. 631-650, 1998.

[24] M. Murata, T. Kuboki, K. Takahashi, M. Goodarzi, and Y. Jin, "Effect of hardening exponent on tube bending," Journal of Materials Processing Technology, vol. 201, no. 1-3, pp. 189-192, 2008.

[25] S. Y. Kim, W. J. Choi, and S. Y. Park, "Spring-back characteristics of fiber metal laminate (GLARE) in brake forming process," International Journal of Advanced Manufacturing Technology, vol. 32, no. 5-6, pp. 445-451, 2007.

[26] H. J. Liu, J. C. Hou, and H. Guo, "Effect of welding speed on microstructure and mechanical properties of self-reacting friction stir welded 6061-T6 aluminum alloy," Materials and Design, vol. 50, pp. 872-878, 2013.

[27] W. Woo, L. Balogh, T. Ungár, H. Choo, and Z. Feng, "Grain structure and dislocation density measurements in a frictionstir welded aluminum alloy using X-ray peak profile analysis," Materials Science and Engineering A, vol. 498, no. 1-2, pp. 308313, 2008. 

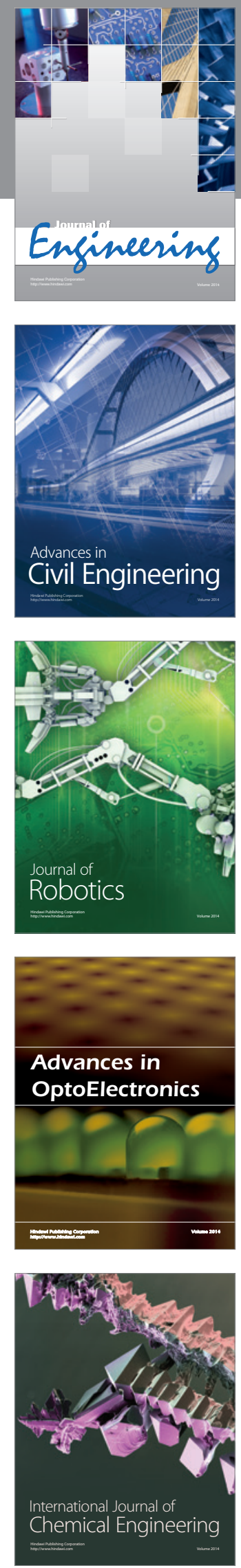

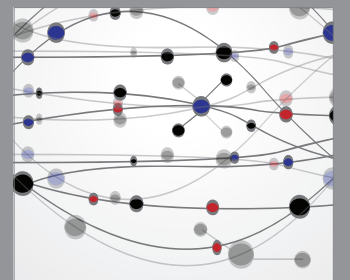

The Scientific World Journal
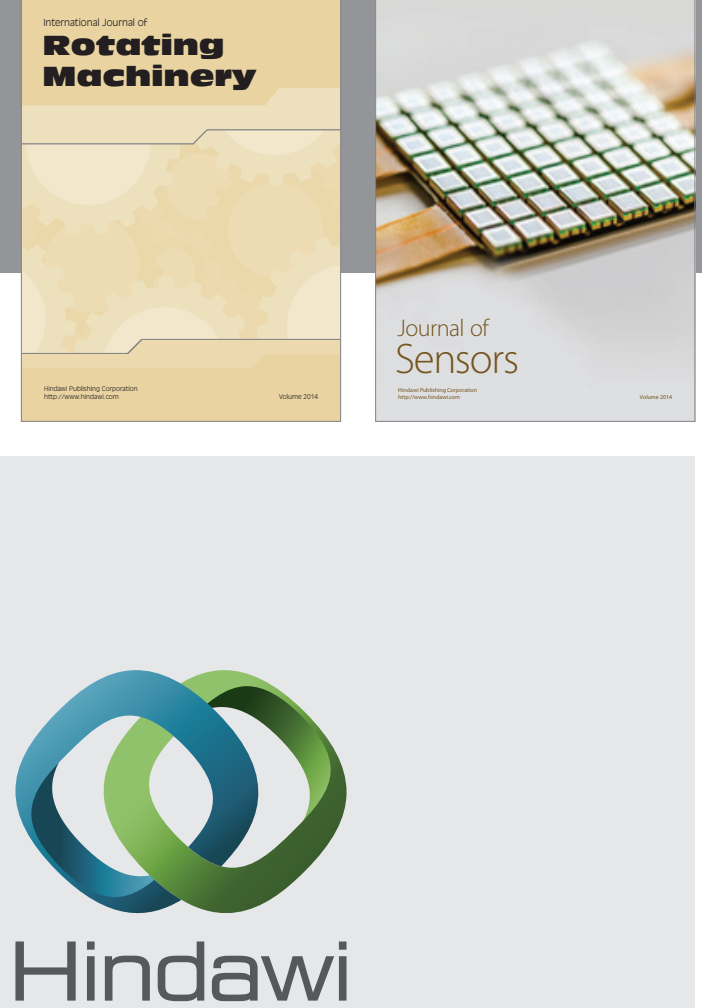

Submit your manuscripts at http://www.hindawi.com
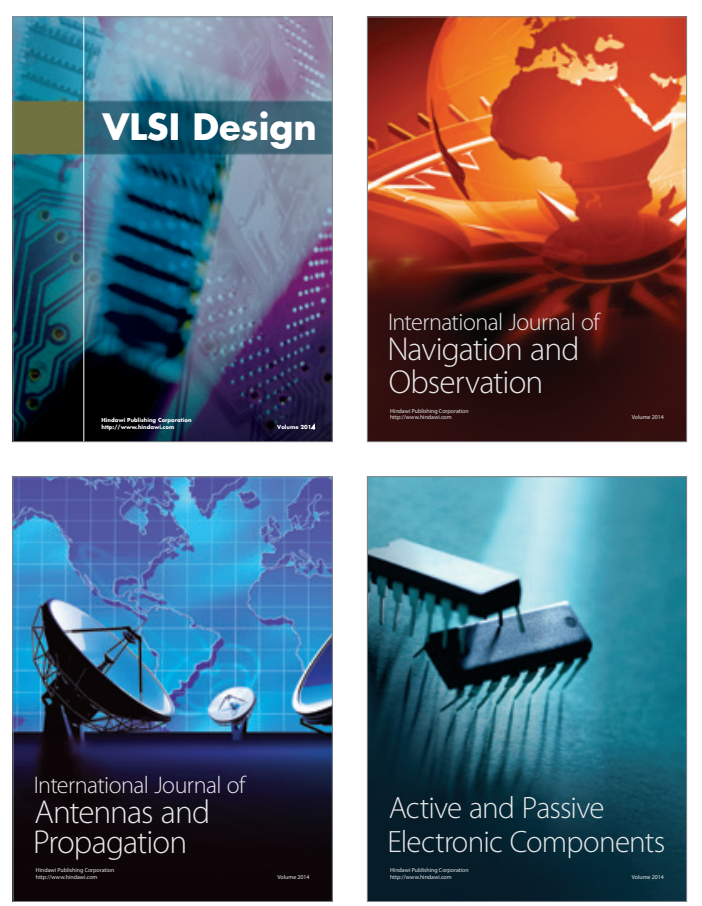
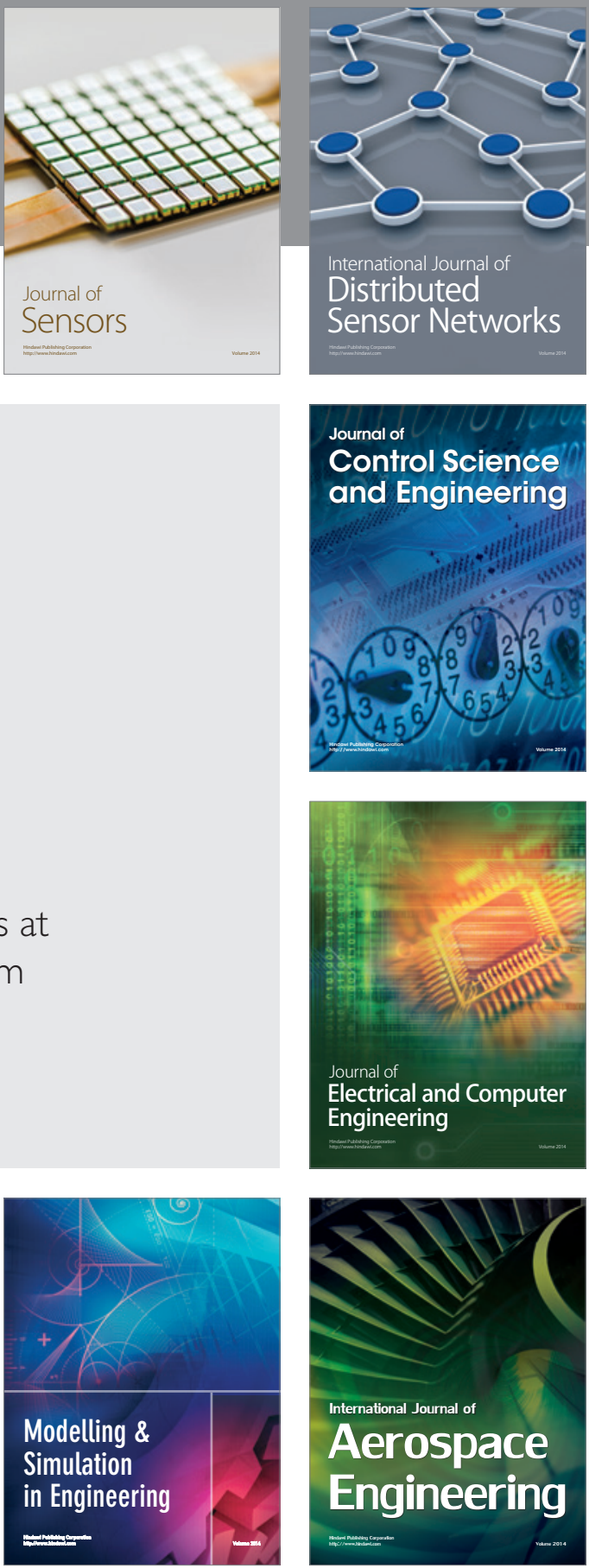

Journal of

Control Science

and Engineering
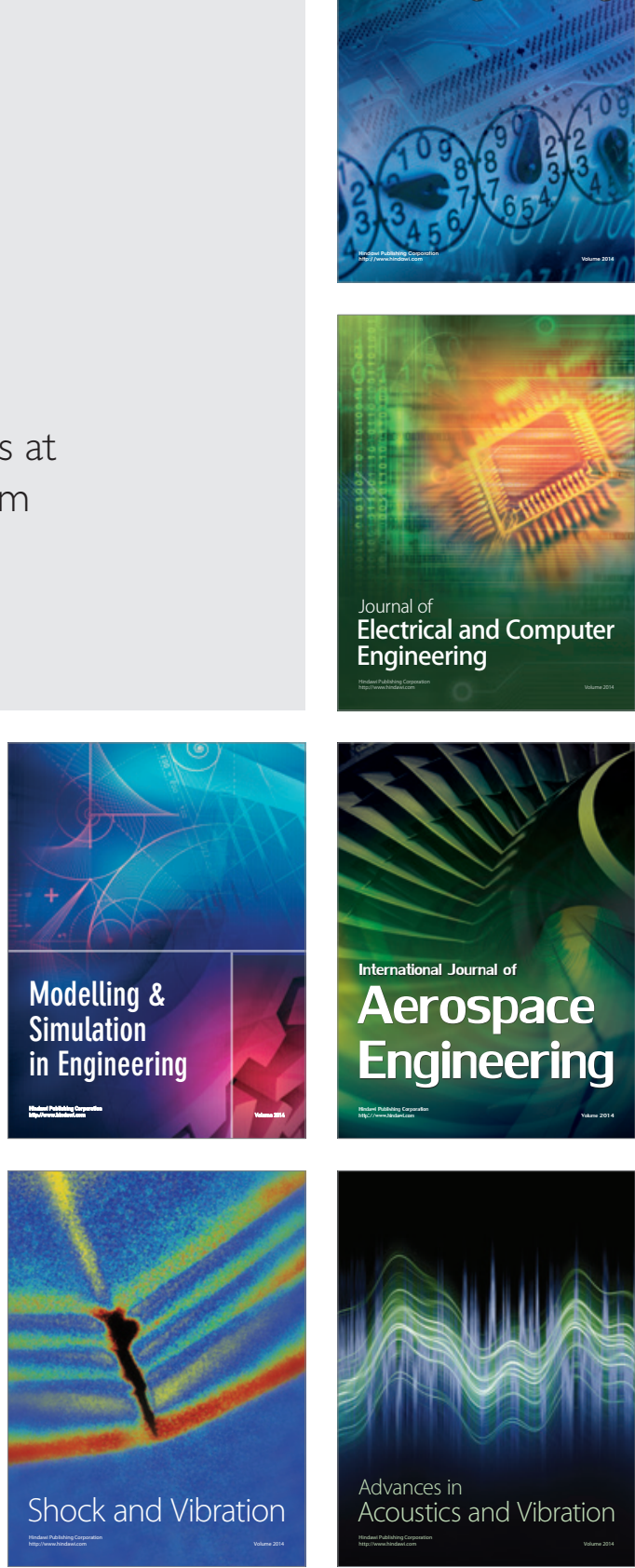